\title{
MÉXICO NO GANA EL ORO QUE GASTA: ESO ES LA CRISIS. POLÉMICAS SOBRE LAS REFORMAS MONETARIAS DE 1931 Y 1932
}

\author{
MEXICO DOESN'T EARN GOLD IT SPENDS: \\ THAT IS THE CRISIS. \\ CONTROVERSY OF MONETARY REFORMS \\ OF 1931 AND 1932
}

\author{
Luis Anaya Merchant* \\ Universidad Autónoma del Estado de Morelos, Morelos, México <luisanay@hotmail.com>
}

Resumen. Este ensayo revisa la reforma monetaria de 1931 y su enmienda de 1932. Un objetivo central es profundizar el conocimiento de los problemas económicos y monetarios que las causaron. La revisión es pertinente por el desequilibrio presente actualmente en la historiografía y los énfasis de su enfoque. Por esto, el ensayo cuestiona la historiografía canónica, sus fuentes y la pertinencia de sus premisas y conclusiones que aquí se examinan a la luz de argumentos y fuentes distintas (algunas contrarias), en aras de construir una visión más equilibrada del momento y de las decisiones que normaron el cambio de políticas monetarias.

Palabras clave: política monetaria; patrón oro; moneda plata; Banco Central.

Abstract. This paper reviews the currency reform of 1931 and its amendment in 1932 . A central goal is to deepen the knowledge of economic and monetary problems that caused them. The review is relevant for the present imbalance in the historiography and the emphasis of his approach. Therefore, the paper questions the canonical historiography, sources and relevance of its premises and conclusions discussed here in the light of arguments and different sources (some contrary), in order to build a more balanced view of the conjuncture and the choices that regulated monetary policy change.

Key words: monetary policy; gold standard; silver coin; Central Bank.

Fecha de recepción: junio de 2012. Fecha de aceptación: febrero de 2013.

* Agradezco las críticas y comentarios de los dictaminadores, así como los de mis colegas Ricardo Solís y Marcos Ortiz.

Am. Lat. Hist. Econ., año 20, núm. 3, septiembre-diciembre, 2013, pp. 170-209 
Ojalá que las crisis económicas las provocara un [solo] hombre, porque así tendrían muy fácil remedio: otro hombre que hiciera las cosas en sentido inverso solucionaría las crisis. ${ }^{1}$

\section{INTRODUCCIÓN}

$\mathrm{L}$ a "última causa" de la crisis -denunció el Congreso Nacional de Economía de 1931- era la referida en el título que da nombre a este artículo. El Congreso fue un intento serio por aclarar las causas principales de los problemas y proponer soluciones. Concurrieron más de 200 ponentes entre funcionarios, hombres de negocios y especialistas. ${ }^{2} \mathrm{La}$ reforma monetaria del 25 de julio de 1931 abrevaría sus ideas, algunas ya presentes en comisiones gubernamentales. El ministro de Hacienda, Luis Montes de Oca, creaba consensos con empresarios y políticos para reorganizar la alicaída economía nacional. ${ }^{3}$ La debilidad del gobierno de Pascual Ortiz Rubio (1929-1932) exigía cautela pues la depresión empeoraba por fracturas políticas, la agitación del campo y las movilizaciones sindicales y empresariales ante la nueva Ley del Trabajo. Este ensayo pretende aclarar las circunstancias y motivaciones de la reforma monetaria de 1931 y su enmienda de 1932. Para hacerlo recorre el camino de la discusión con la historiografía heredada y el examen de la crisis económica de la época, misma que por su mayor complejidad y amplitud rebasa los límites del trabajo.

Dividí el ensayo en cuatro secciones. La primera es introductoria y delinea la Ley de 1931, su enmienda, así como a sus autores emblemáticos. La segunda sitúa los problemas monetarios en relación con los bancarios, la comprensión prevaleciente del patrón oro y con los consensos subya-

\footnotetext{
${ }^{1}$ Luis Montes de Oca, "Editorial", El Sol, 30 de enero de 1931. Cabe mencionar que como a él, al ministro de Hacienda hondureño, Dávila, se lo responsabilizó de la crisis de los "brazos caídos".

${ }^{2}$ Véase "Lo que pasó en el Congreso Nacional de Economía", El Universal, 21 de enero de 1931, refiere a Miguel Palacios Macedo (Consejo de Gobierno del Banco de México), José Castellot (decano del Banco Nacional de México), Enrique Creel (banquero y ex funcionario porfiriano), Sánchez de Tagle (periodista financiero), Octavio Medellín Ostos (director de La Voz del Foro), Narciso Bassols, Daniel Cosío Villegas, Carlos Díaz Dufoo, Salvador Mendoza (funcionarios hacendarios e intelectuales), etc., quienes formaron comisiones de fomento a la agricultura, la industria, de reajuste tarifario, monetarias y para hacer "resurgir" el crédito público y "unificar la clasificación fiscal".

${ }^{3}$ Un esfuerzo que desestima la historiografía, pero relevante en la época, véase, en Montes de Oca, A la Comisión de la Confederación de Cámaras de Comercio -para crear un fondo regulador de la moneda-, en Centro de Estudios Históricos de México Carso (en adelante CEHMC), Fondo Luis Montes de Oca, CMLXXv, doc. 20716, 24 de junio de 1931, y A la Asociación de Banqueros de México -revisando su auxilio en la estabilización monetaria-, en ibid., doc. 21075, 23 de julio de 1931.
} 
centes a la Ley. La tercera revisa la historiografía canónica haciendo un contrapunteo de sus argumentaciones y premisas. La cuarta aclara algunas secuelas de la reforma de 1931 y de su enmienda. Entre las líneas que recorren el trabajo están la discusión de la deuda pública, la agitación política y el papel de los autores de las leyes. Al final ofrecemos unas conclusiones de nuestra investigación.

\section{LAS REFORMAS Y SUS IDEÓLOGOS}

Puede ser que el metal oro no posea todas las ventajas teóricas de un patrón regulado artificialmente, pero no se le había podido manipular y había mostrado ser confiable en la práctica. ${ }^{4}$

En julio de 1931 el gobierno de Pascual Ortiz Rubio determinó reformar el sistema monetario que operaba en el país desde 1918 y que, con pequeñas modificaciones, era el diseñado en 1905 bajo la hegemonía porfiriana. La reforma perseguía disciplinar el mercado monetario (por ser objeto de gran especulación), frenar el deterioro de los términos del intercambio (debido a que caían las exportaciones y las importaciones eran muy inelásticas) $\mathrm{y}$, por consecuencia, propiciar estabilidad y reordenamiento para un crecimiento económico más sano. Claro, su diagnóstico, las herramientas disponibles para alterar los problemas y los resultados esperados de los correctivos eran objeto de polémica, sobre todo, al evidenciarse los efectos de la depresión estadunidense. ¿Hasta qué punto se alcanzaron los objetivos de la reforma de 1931? ¿Por qué su "eficiencia" o "fracaso" no ha sido ponderada bajo los parámetros que esta estableció? Una hipótesis plausible es que la historiografía que la ha analizado es inconsistente al ponderarlos, lo que puede afectar la demostración de sus proposiciones. En todo caso, me ha parecido pertinente revisar sus proposiciones y demostraciones al observar el desequilibrio de sus fuentes directas y la falta de términos de contraste que muestra la historiografía. La hipótesis, las preguntas enunciadas y otras desplegadas en el ensayo intentarán ofrecer una visión distinta de la reforma de 1931 y de su enmienda de 1932.

La Ley de julio de 1931 se gestó en acuerdos perfilados desde 1929 con participación de banqueros, industriales y funcionarios. En síntesis, consistió en preservar el patrón oro bajo el expediente de retirarlo de la

\footnotetext{
${ }^{4}$ Keynes, Tract, 1923, traducido en Keynes, Breve, 1996, p. 34.
} 
circulación, ${ }^{5}$ es decir, conservó como unidad monetaria el peso con equivalencia de 75 centigramos de oro puro (artículo $1^{\circ}$ ), pero reconoció como monedas legales sólo al billete del Banco de México (de aceptación voluntaria, artículo $3^{\circ}$ ), las de plata de un peso y las fraccionarias (incluso cuños de bronce, artículo $2^{\circ}$ ). Las de un peso tenían poder liberatorio ilimitado y las fraccionarias sólo hasta 20 pesos (artículos $4^{\circ}$ y $5^{\circ}$ ); aunque las oficinas públicas las recibirían sin limitación (artículo $6^{\circ}$ ). La Ley atacó la especulación obligando la aceptación de la nueva moneda a su valor nominal para cancelar deudas (artículo $7^{\circ}$ ), así reconocía la delicada posición de bancos y comercios ante clientes cuyos créditos eran buenos pese a no poder solventarlos en oro. En su segundo capítulo, partiendo de análisis que señalaban gran abundancia de plata en el mercado, la Ley exageró cautelas al emitir moneda: el artículo $11^{\circ}$ ajustó la emisión fiduciaria, el $12^{\circ}$ prohibió nuevas acuñaciones de pesos plata, el $13^{\circ}$ autorizó acuñaciones de moneda fraccionaria sólo por fundir monedas circulantes. Su capítulo final estableció mecanismos para integrar la reserva monetaria (artículo $14^{\circ}$ ) compuesta de oro -en barra o monedas- y plata a su valor comercial intrínseco "sin exceder el 3\% de las monedas de un peso en circulación" (artículo $16^{\circ}$ ), su destino (artículo $15^{\circ}$ ) y el propósito de reforzar la reserva al hacer canjes del circulante anterior (artículo $17^{\circ}$ ).

A sus 17 artículos, la Ley agregó quince disposiciones transitorias donde suspendió acuñaciones de oro, declaró su libertad de exportación-importación, exceptuó su entrega a quienes lo recibieron a cuenta de terceros o en depósito confidencial y obligó a la banca a pagar en oro " $30 \%$ de los depósitos a la vista o a plazo no mayor de 30 días" que el público constituyó en esa especie. La cuarta señaló excepciones al artículo $8^{\circ}$ y obligó a que el pago de contratos en divisas extranjeras se hiciera en su equivalente nacional. La quinta privaba de circulación legal al oro y a cuños de plata y bronce referidos en el artículo $2^{\circ}$. De gran importancia, la sexta disposición transitoria relevó al Banco de México de las funciones de administrar la reserva monetaria, definir montos y garantías de la banca comercial, operar el redescuento, etc., por vía de establecer una Junta Central Bancaria formada con el ministro de Hacienda, un delegado del Consejo del Banco de México y cinco delegados de la banca comercial, la séptima resolvía la forma de votación de la Junta Central y daba poder de veto al ministro. La octava, novena y décima definían los lugares de resguardo de reserva y modificaciones a los montos de reserva. La 11a. y 12a. concedían a la Junta Central Bancaria limitar el redescuento y definir sus operaciones con

\footnotetext{
${ }^{5}$ Su parentesco con la Ley Monetaria de 1905 se distanciaba en este punto. En 1905 sí se monetizó oro bajo un patrón "cojo" en el que la plata sólo tenía facultades de moneda de apoyo. En 1931 esto cambió, el oro se desmonetizó y la plata amplió sus capacidades liberatorias.
} 
bancos provinciales. La 13a. y la 14a. remitían impuestos por producción de metales y saldos de la Comisión de Cambios para constituir la reserva. Por último, se facultó a Hacienda para "proveer en la esfera administrativa la ejecución" de la Ley.

La enmienda del 9 de marzo de 1932, que no modificó el patrón oro, fue una reacción pragmática a la falta de liquidez y crédito. Su artículo primero (que modificó el $12^{\circ}$ anterior) permitió al Banco Central acuñar moneda. El segundo modificó el $13^{\circ}$, agilizando trámites para ampliar la oferta monetaria. Integró también tres transitorios; el primero derogó los artículos del $6^{\circ}$ al $12^{\circ}$. El segundo disolvió la Junta Central Bancaria obligándola a devolver las cantidades que le depositó la banca comercial y sus libros contables. El tercero facultó "por esta sola vez" a la Secretaría de Hacienda para acuñar monedas de un peso.

Luis Montes de Oca es considerado el ideólogo principal y casi único de la Ley de 1931 que habría agudizado la contracción económica. Al margen de que la Ley subestimó sus efectos sobre la falta de crédito y liquidez, la historiografía ha desatendido su interés por controlar el mercado monetario para el Estado y desarrollar una moneda sana, objetivos que no eran menores o irrelevantes. La enmienda solucionaría la falta de liquidez pero al costo de diluir estos propósitos de la Ley.

La enmienda terminaría también por depreciar de tajo la gestión montesdeoquista (del 16 de febrero de 1927 al 20 de enero de 1932) que, por cierto, apenas es conocida; incluso menos que otras muy efímeras e intrascendentes. Irónicamente esto sucede pese a ser la gestión más larga del periodo reconstructivo y de aquí la pertinencia de arrojar nuevas luces a su coyuntura final. El ingeniero Alberto J. Pani precedió y sucedió (del 23 de septiembre 1923 al 16 de febrero de 1927 y del 16 de febrero de 1932 al 28 de septiembre de 1933$)^{6}$ a Montes de Oca formando una peculiar secuencia que marcó su relación y la evaluación de sus desempeños. Contador público, Montes de Oca fue un joven antihuertista que destacó como broker, administrador diligente y diplomático. Calles le encomendó organizar el Departamento de la Contraloría como órgano de vigilancia del gasto y elaboración del presupuesto, lo que lo capacitó para asumir la Secretaría de Hacienda. La carrera político administrativa de Pani fue más heterogénea. Transitó de reeleccionista porfiriano y funcionario menor en la Dirección de Aguas a nuevo maderista del Partido Constitucional Progresista y subsecretario de Instrucción Pública; en el carrancismo fue director de los Ferrocarriles Nacionales, ministro de Comercio y embajador en Francia; reconoció a Obregón quien lo nombró presidente del Comité de Fiestas

\footnotetext{
${ }^{6}$ Durante el intervalo del 20 de enero al 16 de febrero, el subsecretario del ramo, Rafael Mancera, estuvo a cargo del despacho.
} 
del Centenario de la Independencia, canciller y secretario de Hacienda en medio de una disputa con Adolfo de la Huerta. Su enmienda del 9 de marzo de 1932 es considerada como el inicio de la recuperación económica.

La Ley de 1931 y su enmienda diferían en torno a la naturaleza de la crisis, su relación con la masa de dinero circulante, la emisión fiduciaria y sus garantías, la política del redescuento y el combate a la especulación. Sin duda, la Ley subestimó la contracción monetaria y sobrevaloró los consensos alcanzados con el comercio, la industria y la banca. En paralelo agregó objetivos que la complejizaron: la reorganización del Banco de México, crear su reserva y modificaciones a la operación de la banca comercial. La falta de liquidez no era la causa de la crisis pero catalizaría tensiones que la agravaron. La enmienda destensaría la "tirantez" y liberaría factores productivos pero el periodo de dinero barato y abundante que la acompañó no resolvió los problemas sustantivos e incluso germinaría una dinámica inflacionaria. En lo que sigue observaremos algunas de las razones, alcances y circunstancias que condujeron a la decisión de 1931.

\section{LAS COMPLICACIONES DEL DIAGNÓSTICO}

Los problemas monetarios al finalizar los años veinte eran producto de herencias porfirianas que la revolución y los efectos de la depresión estadunidense agravaron. Un "sistema" bancario inmaduro, marcadas estacionalidades productivas en una geografía económica con deficientes circuitos de comercialización, escasez de moneda menuda y hábitos culturales distintos ante la moneda delineaban, en grandes trazos, esos problemas. Las circunstancias en que operaron los hacendistas revolucionarios eran más apremiantes e inestables; menos expertos que sus antecesores cometieron errores, enfrentaron intereses y ensayaron cambios inconsistentes. Fue común que lo ensayado por un gobierno el siguiente lo ignoraba o anulaba. Tal lógica de "marcha y contramarcha" se originaba en la violencia que subyacía a los cambios de régimen; claro, esas inconsistencias y giros dificultan evaluar la eficiencia de las reglas implementadas. Como ejemplo de tal "lógica" se podría advertir que Pani eliminó pasos andados por su antecesor Montes de Oca (por ejemplo, disolvió la Contraloría y sus programas de profesionalización), ${ }^{7}$ pero en septiembre de 1933 discutía con Plutarco Elías Calles porque aún no entregaba buenas cuentas. En 1925, Pani logró un gran cambio imponiendo el impuesto sobre la renta justificado en los gastos extraordinarios de la rebelión delahuertista. Sabiendo

\footnotetext{
${ }^{7}$ Véase Pani, Obsesiones, 1953, p. 228. Al cerrar la Contraloría ahorró 3100000 pesos, eliminó algunos empleos y redujo el control del ejecutivo sobre el gasto del sector público.
} 
que añadir gravámenes sería impolítico, Montes de Oca privilegió aspectos administrativos: profesionalizó personal, sistemas internos, favoreció la estabilidad arancelaria, impidió cambios sin revisión pero no continuó las convenciones fiscales que inició Pani. Entre avances y retrocesos, la economía siguió siendo frágil pese a los esfuerzos reconstructivos, crediticios, agrícolas y al auge de exportaciones mineras que ya tendían a depreciarse. El desorden agrario, el monetario, la falta de personal capacitado y de crédito, la fragmentación del mercado interno, la quiebra de fiscos estatales y otras inoperancias institucionales debilitaban la economía.

Al iniciar la década de 1930 la población descreía de promesas revolucionarias que no aliviaban sus males pero sí enriquecían a líderes que reducían la participación política a cotos cerrados donde se ascendía por oportunismo o "pistolerismo". Los conflictos laborales y agrarios se dirimían a balazos o, en el mejor de los casos, con burocracias interesadas o débiles. En la industria eran interminables las disputas sindicales y en el agro florecían "políticas" disolventes que repartos posteriores acentuarían, aunque en algo legitimaban anhelos de cambio.

Es pertinente anotar que la polarización afectó el debate monetario, de por sí oscurecido en la lenta degradación del patrón oro al que muchos contemporáneos creían viable y al que la reforma seguía cautamente, por principio, desmonetizando el oro. Del reciente fracaso de los tipos de cambio flexibles en Alemania, Austria y Hungría se sabía que sería difícil reemplazarlo mientras, en el día a día, el oro se comerciaba y aceptaba. Nunca se han exentado de dudas y prejuicios teóricos los problemas monetarios y esa época agregó a su incertidumbre el cuestionamiento de teorías consideradas válidas, como la cuantitativa; es decir, la cantidad de moneda determinaba el volumen de los negocios. Valga anotar que la Ley de 1931 descansó en un horizonte distinto, el volumen de negocios definía la demanda de moneda; había que incentivarlos para fortalecerla. Pero la depresión desincentivaba y el régimen bimetálico de facto añadía complicaciones al ambiente de los negocios. Además, el régimen se desordenaba y descomponía por razones estructurales, como la propia inmadurez de la economía, sus regionalismos, el "ausentismo" de capitales y por motivos más relacionados con la coyuntura, como la especulación o la caída de las exportaciones. Veamos ahora algunas implicaciones (laborales, monetarias, crediticias, etc.) de estos fenómenos.

El denominado "ausentismo" del capital extranjero que participaba en sectores extractivos consistía en invertir el mínimo capital y exportar la mayoría de las utilidades. En el fenómeno concurrían tensiones importantes, lo criticaba la opinión pública, pero cámaras de comercio e industriales abogaban por su statu quo, mientras los ministerios de Hacienda o de Industria titubeaban en modificar la práctica, pues reportaban ingresos 
fiscales, generaban empleos y no era fácil de regular, como lo verificaba el amplio contrabando de oro durante la crisis. ${ }^{8}$

La especulación de moneda plata fue un punto álgido de la discusión pública. Analistas y autoridades acusaron a la banca de agudizar la devaluación para lucrar y no les faltaba razón, pues abusó del descuento sobre la moneda plata, el premio pagado al cambiarse por oro. Claro, el premio crecía con la escasez del oro, reconociéndole ser la moneda de reserva internacional. Esta era la "base natural" de especulación (su tipo rondó $3.5 \%)^{9}$ manifiesta, por ejemplo, en la imposibilidad de controlar su contrabando o en la conducta de "ahorradores nacionales" que preferían contratos oro en bancos extranjeros. ${ }^{10}$

La especulación reflejaba la repugnancia de los ahorradores a las fluctuaciones de la plata. Por ello, las sucursales de bancos extranjeros (presumiendo solvencia en sus matrices) fueron los grandes ganadores de tal ambiente. Su historia es reveladora; el último en desaparecer del mercado por razones peculiares fue el Banco Mexicano de Comercio e Industria. ${ }^{11}$ Los más visibles, el Germánico de la América del Sud, el Anglo-South American Bank Ltd., el Canadian of Commerce y, el más importante, con siete oficinas en el país, el Banco de Montreal florecían en la década de $1920 .^{12}$ Pese a evidentes signos de deterioro en la economía, en 1928 había diez entidades y doce en 1930, gracias a la llegada de bancos estadunidenses. La preferencia del público los fortalecía, pero su desregulado comportamiento (migrar utilidades sin reinversión, baja colocación de créditos, etc.) no benefició a la economía real.

Los antiguos bancos de emisión (ahora, refaccionarios) tampoco ayudaban mucho, incluso objetaban al Banco de México. Su descontento venía de haberles quitado el negocio de la emisión y de competirles comercialmente. La revolución los mostró como icono del porfiriato, por lo que recordaba sus abusos y la necesidad de "democratizar el crédito". Las

\footnotetext{
${ }^{8}$ La encrucijada de tensiones se muestra en la pervivencia del problema durante el cardenismo. Véanse ejemplos de la preocupación de Hacienda en Excélsior, 17 de septiembre de 1928; de presión pública en El Nacional Revolucionario, 27 de abril de 1931, y de intercesión de intereses comerciales en Excélsior, 12 de febrero de 1932.

${ }^{9}$ Este tipo de descuento se pagaba en marzo de 1929, véase Acta 192, en Archivo Histórico del Banco de México (en adelante AHBM). Al arreciar la crisis se vieron descuentos superiores a 14 por ciento.

${ }^{10}$ Menos se ha atendido la especulación de plata; un procedimiento era canjear antiguos pesos plata comprados en China por "los actuales", ganando hasta catorce centavos de dólar por peso, véase Acta 242, 14 de febrero de 1930, en AHBM.

${ }^{11}$ Véase Anaya, "Banco", 2007.

${ }^{12}$ En 1925 tenían 58200000 de 154800000 pesos de los depósitos totales (pesos y divisas) del sistema bancario. En 1927 tenían 84000000 de 200000 000; pasando de 37 a 42\% del ahorro público. Su captación de divisas subió de 19200000 a 27000000 de pesos en el mismo periodo, véase Comisión, Sexto, 1928.
} 
tensiones y experiencias pasadas aún pesaban, mientras que las deudas insolutas del gobierno con dichos bancos proveían a estos de argumentos y capacidad negociadora para resistir el intervencionismo estatal. ${ }^{13}$ Huelga señalar que en medio de la crisis sus previsiones de riesgo los desalentaban a colocar nuevos créditos y los alentaban a cobrar los ya contratados. La banca estatal hacía todo lo posible por contrarrestar la falta de crédito pero sus efectos en la coyuntura eran similares a los anteriores, aunque también eran más pequeños, politizados y poco eficientes. En 1931 se optó por reorganizar al Banco de México, entre otras razones porque se lo veía más ocupado en sus funciones subsidiarias que en las esenciales. Justificado en esto y en que no se alterarían los parámetros crediticios generales, canceló sus operaciones directas con el público; de hecho ya había reducido su crédito directo para sanear su cartera. ${ }^{14}$ Lo que no tuvo mayor impacto en la oferta crediticia general, estancada durante 1928-1930 y disminuida en 1931-1932 (pequeñas variaciones favorecieron los préstamos comerciales, pasando de 139000000 a 181000000 en el primer periodo, mientras los refaccionarios e hipotecarios descendían). La cancelación de su sistema de sucursales alentaría la formación de nuevas entidades financieras después de 1934, pero también resurgieron tendencias a la concentración. Todo lo cual no alteró el hecho de que la vida del crédito nacional fuera misérrima. Su precariedad es un problema que suele subvalorarse frente al de los instrumentos de cambio.

Otro desajuste venía de la depreciación metalífera. La "canasta" de metales exportados era más diversa pero no solucionaba las pérdidas laborables ni fiscales. La caída del precio de la plata (34\% de 1928 a 1930), ${ }^{15}$ sometida a poderosos factores externos -entre estos, la desmonetización china o la venta de reservas hindúes ${ }^{16}$ golpeaba con fuerza la economía mexicana.

${ }^{13}$ Durante esta crisis se revitalizaron los trabajos de la Comisión que liquidaba los adeudos con estos bancos, véase Acta 248, 4 de abril de 1930, en AHBM.

${ }^{14}$ Véase Acta 215, 9 de enero de 1931, en AнвM. Sobre las inmovilizaciones que arrastraba véase Anaya, Banco, 2011. Montes de Oca no creía que la miseria crediticia se pudiera corregir con sus préstamos directos que incluso parecían frenar la multiplicación bancaria. Sin duda, en la época se sobredimensionaron sus funciones y su capacidad para resolver problemas. Si bien él tenía una opinión crítica de la eficiencia de la intervención del Estado en la economía no defendió fanáticamente la desregulación.

${ }^{15}$ Un cálculo oficial señala que en 1929 se produjeron 108700000 onzas plata (40\% del total mundial). Ahora bien ¿cómo cotizarla? ¿a los 0.60 centavos de dólar de la paridad de 1928 o a los 0.25 centavos de dólar de 1930?, véase Gurría, Consideraciones, 1934, pp. 8 y ss. El Nacional Revolucionario, 20 de febrero de 1931, estimó su caída en valor en 25000000 de pesos en 1930. Más difícil de cuantificar es la pérdida de empleos por cierre de minas, en 1934 se estimaba en 110000 el número de operarios directos.

${ }^{16}$ China e India eran los principales mercados de la plata. No obstante la diversidad de cálculos, en Gurría, Consideraciones, 1934, no es exagerado suponer que comerciaran dos terceras 
En relación con la depreciación argentífera es necesario atender un punto que contraria muchas apariencias, la relativa constancia del valor de la moneda plata pese a su declive metálico. Incluso la coyuntura parece más caracterizable como un proceso de apreciación áurea que de depreciación del peso plata. Ciertamente, sólo es un matiz pero contribuye a aclarar -no justificar- por qué se favoreció la política de estabilidad monetaria. La relativa constancia se apreciaba en los números generales de intercambio contra el dólar y el oro. A semanas de operar la Ley de julio, la plata mostró altibajos -en la primera y segunda semanas de septiembre osciló de 34.5 a 40.45 centavos de dólar por peso, en Nueva York- que llevaron a la Junta Central Bancaria a recomendar un punto de equilibrio relativamente bajo para el peso: tres por dólar (33 centavos de dólar). ${ }^{17}$ Sin embargo, dos eventos externos modificaron el escenario de la plata, el 20 de septiembre de 1931 Inglaterra suprimió el patrón oro. La decisión se adoptó por la imposibilidad de descontar la libra en oro ante su enrarecimiento debido a las remesas enviadas a Estados Unidos en pago de deudas y a recientes fugas hacia Francia. La decisión inglesa respaldó la intención del $4^{\circ}$ Congreso Comercial Panamericano de promover la rehabilitación de la plata para alentar su mayor uso monetario. Estos eventos fueron cambios favorables al mercado de la plata, que comenzó a mostrar un comportamiento que semejaba un bien Giffen (subió de precio pero su demanda aumentó), ${ }^{18}$ llevando al peso a un punto de equilibrio más alto, como se aprecia al final de 1931. Así, la "ortodoxa" reforma monetaria alcanzó su punto de mayor aprobación gracias a "externalidades". Pero las bondades de la revaluación del peso no eran claras, prevaleciendo un grave estancamiento y una rígida estructura de importaciones. Dados el desequilibrio presupuestal y la balanza deficitaria tampoco era predecible que la paridad se estabilizara en un punto alto. El cuadro 1 nos da una idea de la relativa constancia del valor de la plata.

La relativa constancia del peso plata se explicaba -en parte- por un ciclo más largo de descenso (al que respondía su sustitución) y porque siendo un proceso mejor conocido las autoridades la intervenían periódicamen-

partes de la producción mundial. En esta época los profundos disturbios que sufrían alteraron su comercio exterior y significaron presiones a la baja del precio y atesoramiento del metal blanco.

${ }^{17}$ La mayoría de la prensa dio la noticia el 15 de septiembre de 1931.

${ }^{18}$ El comportamiento se explicaba, como en el caso del oro, en la búsqueda de refugios de valor que hacían los agentes económicos en condiciones de gran incertidumbre internacional. Cabe observar que si bien la plata se empleaba cada vez más en usos industriales (como una mercancía ordinaria), no era un "bien inferior" en el sentido en el que teóricamente "caen" los bienes Giffen. La plata, pese a su continua depreciación, es un metal precioso y su revaluación recordó que era un activo financiero válido y su demanda se regiría, como antes, por la expectativa de su precio futuro. Aquí se separaba de la explicación de los bienes Giffen. 
te. ${ }^{19}$ Pero esa tendencia se oscurecía al combinarse con la preferencia áurea de los agentes. Preferencia que, como advertimos, se contrarrestó por la decisión inglesa, la formación de un bloque panamericano, el Acuerdo de Londres de 1933 y el Acta roosveltiana de compras de plata de 1934, que la rehabilitaron monetariamente. La aversión al riesgo había encontrado su asidero en el oro pero el final de 1931 convocó una contramarcha y para el mercado mexicano un inesperado vuelco. No obstante que los juicios sobre la plata no siempre fueron certeros, las nuevas circunstancias justificaron a quienes observaban que la inestabilidad embozaba una relativa constancia de la plata. La gráfica 1 muestra el comportamiento de ambos metales, suavizada por su expresión en unidades de desviación estándar (eje Y), y ayuda a apreciar la tendencia señalada (lo hace porque muestra el comportamiento estadístico de los metales al remover otras unidades o magnitudes que pudieran ensuciar la trayectoria. Es decir, omite otros valores para mostrar en forma pura el comportamiento estadístico de la serie, pues de otra forma se generarían índices y se perdería la estructura de la formación del precio y, con ello, poder descriptivo). Es improbable que las autoridades hicieran este ejercicio pero no hay duda de que comprendían -contra el sentido común- la relativa constancia del peso plata. De aquí partía su idea de intentar estabilizar en una paridad moderadamente cercana puntos de equilibrios de 1930.

El cuadro 1 y la gráfica 1 revelan que hacia septiembre de 1930 inicia el momento monetario más crítico, que alcanza su punto climático en abril de 1931. Para entonces habían ocurrido varias intervenciones de la autoridad. Luego de la reforma hubo movimientos de ajuste siendo el más importante la salida inglesa del patrón oro, que movió el peso a un punto de equilibrio alto: 2.60 pesos por dólar. ${ }^{20}$ La enmienda de marzo de 1932 modificaría objetivos previos y lo situó en un punto de equilibrio bajo, 3.60 pesos por dólar, depreciación que fue más importante de lo que aparenta porque la mayor parte de los costos fiscales, laborales y bancarios ya habían sido amortizados.

${ }^{19}$ La falta de un fondo regulador impedía intervenir más eficientemente, pero después de 1927 el recurso se empleó más para retirar plata (pues era relativamente abundante) que para inyectarla, véase Acta 191, 7 de marzo de 1929, en Анвм.

${ }^{20}$ Observador atento, William McEntee, de la embajada estadunidense, vio la mejoría. Pensó que en diciembre se fijaría en 2.50 pesos, atribuyéndolo a que el gobierno "no cambia caballos en medio del río, mientras el trabajo del nuevo sistema monetario no esté completado", en CEHMC, fondo Luis Montes de Oca, CMLXXV, doc. 22334, 23 de octubre de 1931. 


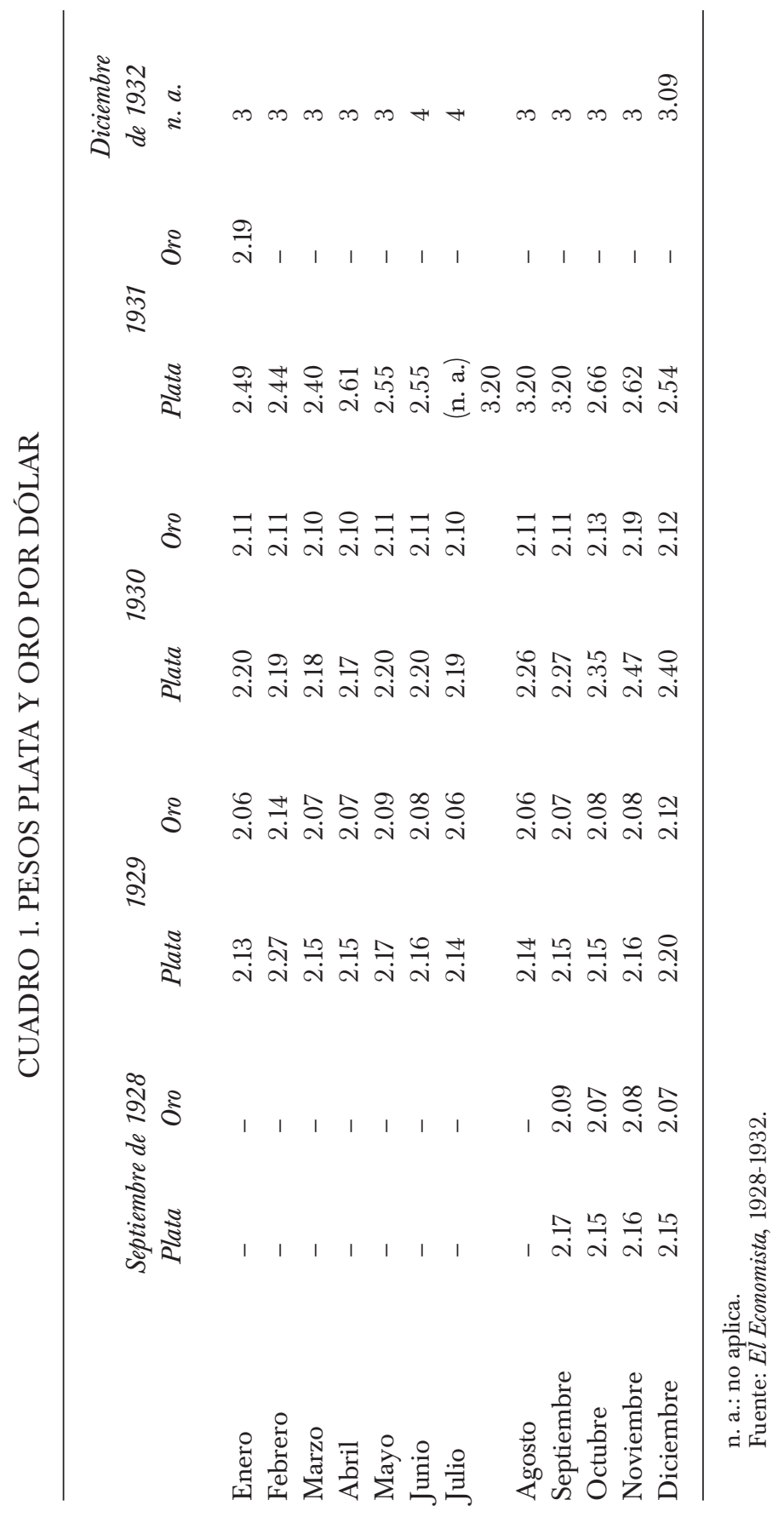




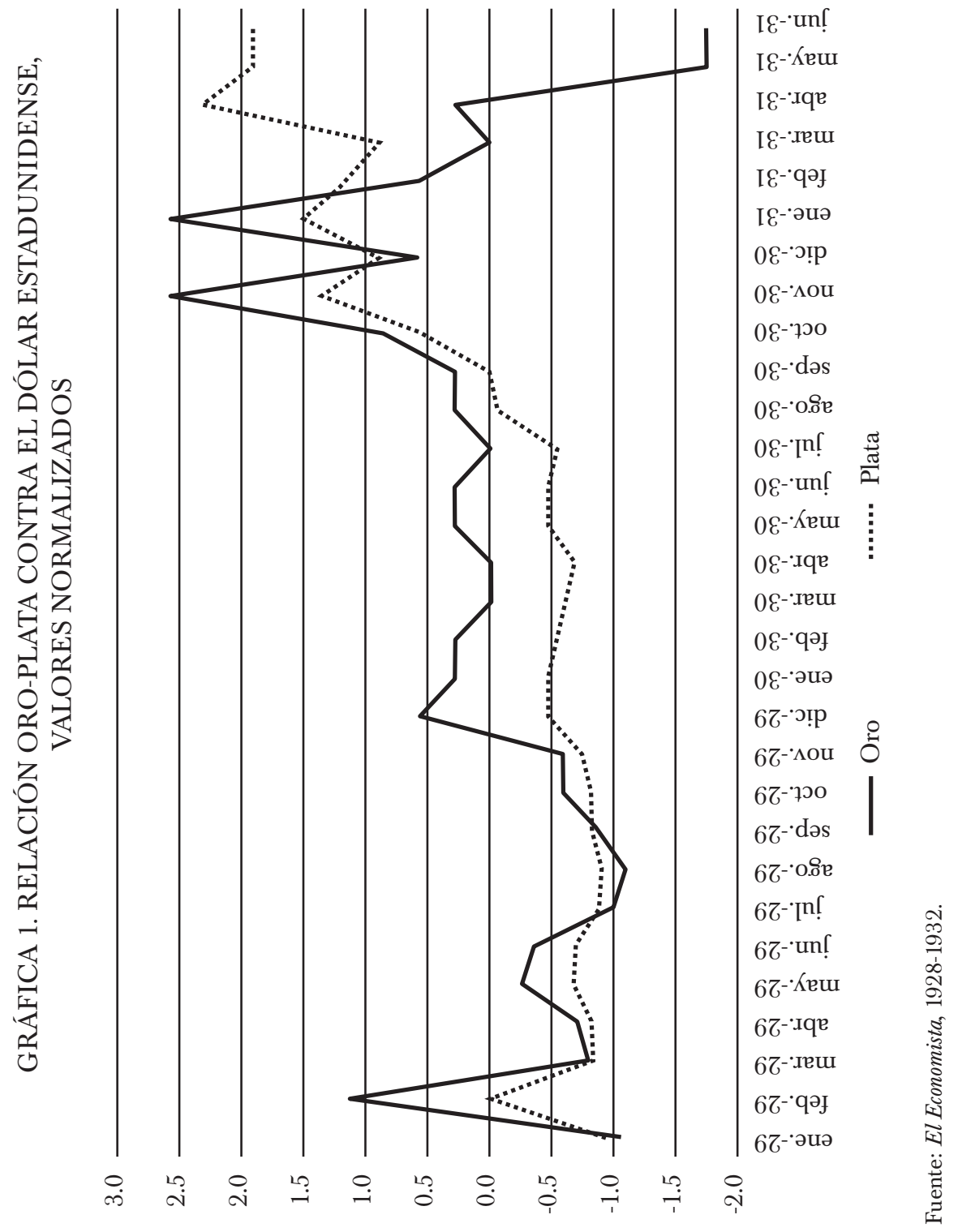




\section{Consensos}

En la historiografía se insinúa que la Ley de 1931 fue concebida rápida y exclusivamente por la alta burocracia de la Secretaría de Hacienda. Esto es equívoco, su concepción fue retardada y ocurrió así porque fueron escuchadas propuestas de actores económicos. Ya en abril de 1930, sectores comerciales se pronunciaban por rehabilitar la plata. En junio, el Consejo de Administración del Banco de México formó una comisión para estudiar los problemas monetarios y propuso revalorizarla. ${ }^{21} \mathrm{Al}$ ocurrir su mayor descenso, Montes de Oca negociaba en Nueva York la deuda externa y se le señaló que la baja sería pasajera. ${ }^{22}$ La Comisión destacó como causas la especulación áurea ${ }^{23}$ y el exceso de circulante plata, y aconsejó distinguir problemas de su estatus como metal industrial y como moneda. A su regreso Montes de Oca revaloró la situación. Pronto surgió la idea de suspender el acuerdo que había alcanzado, decisión que se formuló como moratoria. ${ }^{24} \mathrm{El}$ consenso se orientaba a detener la depreciación del peso por sus impactos negativos en el costo de la vida; el Banco de México compró plata para regular los excesos y aumentó los intereses para depósitos bancarios en plata, sin embargo, advirtió la dificultad de continuar con estas medidas pues la depreciación era causada por la contracción económica y la escasez de oro. A esto se añadía el contrabando. ${ }^{25}$ Valga citar una estimación cauta de octubre, cuando se acuñó oro por valor de 1500000 pesos y salió el doble. ${ }^{26} \mathrm{~A}$ la fuga contribuían prácticas bancarias y la baja de precios estadunidense que estimulaban más importaciones que no podían ser reemplazadas por artículos nacionales dadas sus deficiencias e insuficiencias. ${ }^{27} \mathrm{Al}$ decidir continuar en el patrón internacional dominante y careciendo de reservas no podía sostenerse una política monetaria

${ }^{21}$ Véanse Actas 257 y 258 del 6 y 10 de junio de 1930, en AнBм.

${ }^{22} \mathrm{Ibid}$., es plausible que las opiniones de los consejeros del banco influyeran en la percepción del subsecretario Rafael Mancera, quien señaló a Montes de Oca que la situación mejoraría al recaudarse el impuesto sobre la renta y de la gasolina, véase CEHMC, fondo Luis Montes de Oca, CMLXXV, doc. 17642, 14 de julio de 1930.

${ }^{23}$ Véase Acta 277, 19 de agosto de 1930, en AHBM. Mascareñas estimó en 9000000 de pesos la disminución de la reserva y manifestó su preocupación por su incrementado contrabando.

${ }^{24}$ Lo que finalmente ocurrió; el 28 de enero de 1931 quedó sin efecto el Convenio Montes de Oca-Lamont; el 11 de enero de 1932, Ortiz Rubio solicitó al Congreso cancelar cualquier pago hasta 1934.

${ }^{25}$ Fenómeno recurrentemente referido por autoridades y prensa pero cuya naturaleza impide cuantificarlo y diferenciarlo de atesoramientos. México no era un gran productor de oro pero es plausible que lo haya producido por valor de 500000000 de pesos entre 1905 y 1931. En 1931 se estimó que las reservas de la banca comercial oscilaban apenas en 50000000 de pesos oro.

${ }^{26}$ Véase Acta 289, 3 de octubre de 1930, en AнBм.

${ }^{27}$ Véase Acta 337, 24 de marzo de 1931, en AHBM. México importó mucha maquinaria de segunda mano y por los programas reconstructivos del gobierno. Empresas de comunicaciones (ferrocarriles, aviones, autotransporte, etc.), sector energético y minería eran rígidas en su demanda. 
autónoma. Aceptar liberar el comercio áureo era una consecuencia lógica y no sólo la constatación de la escasez de oro en el mercado. Lo prudente de la Ley de 1931 fue desmonetizarlo y convertir deudas áureas a plata; medidas heterodoxas que revelan pragmatismo e interés por frenar la especulación castigando a sus practicantes. ${ }^{28}$

El panorama enfrentado era peculiar. Legalmente México vivía bajo el régimen monetario oro de 1905 (reformado en 1918) apoyado en un instituto emisor central estatal pero, en realidad, obedecía a un régimen bimetálico inconstitucional (con plata se liberaban pagos al gobierno, mercantiles, giros en oro, etc.) y carecía del auxilio de instituciones de crédito. Por otra parte, la especulación dificultaba al peso plata cumplir con sus funciones legales como moneda de apoyo. ${ }^{29}$ De manera que si la moneda ofrece un pulso de la economía, para diagnosticar la mexicana había que comprender dos débiles diástoles y sístoles en asimetría simultánea. Los fenómenos de degradación monetaria son muy conocidos en la literatura económica y muestran que dos metales pueden compartir la función de tasar mercancías, siempre que no se altere su relación recíproca de valor, pues de alterarse enseña lo contrario, que la duplicación de la medida de valor contradice tal función. Y, claro, la futura adjudicación legal de la función será objeto de pugna, en parte por el desacuerdo de intereses y diagnósticos.

$\mathrm{Al}$ modificar el patrón existente se destacó la regulación de los excedentes de moneda plata (estimados en 50000 000-70 000000 de pesos). Sobre este punto había una experiencia previa reciente. En otra caída de la plata (1927), Montes de Oca limitó excedentes y equilibró el circulante con las necesidades comerciales. Pero las circunstancias eran estables, no hubo shocks externos ni la brutal contracción de ingresos estatales. En cambio en 1930 la degradación del régimen bimetálico se agravó al combinarse los círculos viciosos descritos con la depresión estadunidense, que azuzaron la especulación, ${ }^{30}$ la contracción crediticia y el desempleo. La gravedad del fenómeno requería una atención general.

\footnotetext{
${ }^{28}$ Por lo que no se desarrolló sólo bajo el estrecho dilema planteado por críticos posteriores: “isostener el nivel de cambios o el de precios?". De hecho no sostuvo al primero.

${ }^{29}$ Vellón o "apoyo", donde su valor relativo se debe a la confianza en el gobierno que la acuña, pues su precio intrínseco (cualquiera que sea su metal o aleación) es irrelevante. Las autoridades mexicanas sabían que el precio del metal blanco era oneroso para el circulante de apoyo.

${ }^{30}$ Manifestaciones comprensibles eran el contrabando áureo y la preferencia de "ahorradores nacionales" por contratos oro en bancos extranjeros. Pero también se abusó del descuento sobre la moneda plata hasta el punto de que escaseó. En realidad no se han atendido todas las aristas de la especulación argentífera durante esta coyuntura; uno de sus procedimientos era canjear antiguos pesos plata comprados en China por "los actuales", con lo que se ganaban hasta catorce centavos de dólar por peso, véanse Actas 191 y 242, 7 de marzo de 1929 y 14 de febrero de 1930, en Анвм. En el verano de este año, las circunstancias cambiaron dramáticamente.
} 
$\mathrm{Al}$ arreciar la crisis, en octubre de 1930, Montes de Oca buscó consensos entre los banqueros. Le propusieron elevar intereses por depósitos plata o sus garantías (de 33 a 50\%); él lo rechazó porque podría acentuar la restricción crediticia. ${ }^{31}$ Se eligió elevar garantías por creerse el ajuste más moderado pero, poco después, el Banco de México cambió la medida por incrementos graduales de intereses vigilados por la Comisión Bancaria y de Valores, el Banco y Hacienda, que ya se coordinaban en la regulación; ${ }^{32}$ por supuesto que la especulación, la restricción de nuevas acuñaciones y la poca demanda de billetes también regulaban los excesos. Los efectos de la nueva regulación se combinaban con otros más profundos: estacionalidades y regionalismos productivos, dispersión poblacional, lentitud circulatoria y tendencias al atesoramiento. Estos fenómenos redundaban en súbitas faltas de liquidez. Sin duda, los reformadores de 1931 subestimaron los efectos potenciales de la iliquidez, sobre todo al confiar la flexibilidad de la oferta dineraria al billete..$^{33}$ Notoriamente aquí la reforma falló. Amén de las diferentes expectativas subsistentes entre el público y las autoridades ante la creación de moneda, el Banco de México se descoordinó de los objetivos de la Ley al crearse la Junta Central Bancaria. Los problemas eran reales -medios escasos y desorganización-y de percepción. Al iniciar agosto, Calles ofreció impulsar cambios a la Ley reglamentaria del artículo 28 constitucional para agilizar el redescuento, pero sólo hasta noviembre su acuerdo se atendió en el Banco. ${ }^{34}$ La descoordinación desalentaba y explicaba parcialmente la falta de crédito. En septiembre el redescuento con los bancos asociados sumó apenas 12000000 de pesos; las cosas iban muy lento y en paralelo la banca comercial cobraba activamente y restringía sus créditos, lo que deprimía más la actividad económica. Al final de 1931 se multiplicaron las voces que demandaban nuevas emisiones de billetes, pero las fórmulas ofrecidas para garantizarlas, como hipotecas y pignoraciones, fueron rechazadas por la Junta Central Bancaria. Igual se demandó que el Banco de México regresara al préstamo directo, ${ }^{35}$ pero también se rechazó. Finalmente, el presupuesto incluyó una partida para emitir poco más de 11000000 de pesos bajo un buen respaldo.

Durante el tiempo que se aplicó la Ley se avanzó en el control del mercado monetario pero la conducta de la banca no se alteró; continuó

${ }^{31}$ Véase Acta 294, 21 de octubre de 1930, en AHBM

${ }^{32}$ Véanse Actas 308 y 315, 9 de diciembre de 1930 y 9 de enero de 1931, en AHBM. En diciembre el retiro ascendió a 10000000 de pesos.

${ }^{33}$ Que se crearían sobre la base de operaciones de redescuento respaldadas en activos reales.

${ }^{34}$ Véase Acta 366, 12 de agosto de 1931, en AHBM, Calles se comprometió a gestionarla ante el secretario de Industria y Comercio, Luis L. León, de fondo estaba el asunto de prestar por pignoración. Hasta el 18 de noviembre se definieron las normas para la emisión fiduciaria por redescuento, véase Acta 381, 18 de noviembre de 1931, en AHBM.

${ }^{35}$ Véase Acta 366, 12 de agosto de 1931, en AHBM, y nota 14. 
cobrando "con apremio y sin consideraciones" y tampoco hizo nada para cubrir el hueco financiero que dejó la salida del Banco de México. Un obstáculo que encontró para prestar fue la carencia de papeles comerciales adecuados a las normas de redescuento exigidas por la Junta Central Bancaria. El control, las exigencias y la crisis erosionaban los consensos previos. Había además otro motivo de disenso: la caída presupuestal.

\section{Disensos y presupuesto}

La historiografía suele omitir que la multicitada crisis se enfrentó con un Estado pequeño, ineficiente e institucionalmente dividido que vivía su peor caída de ingresos. Dado su estrecho marco de acción, la Secretaría de Hacienda dedicó buen tiempo a revisar las experiencias de otros países antes de diseñar su política económica. Cuidó limitar el número de impuestos adicionales a un par, una contribución extraordinaria de $1 \%{ }^{36}$ y otra dirigida a los pensionados gubernamentales. Para estimular el gasto, descargó del impuesto sobre la renta a contribuyentes que ganaran menos de 10000 pesos (que era un ingreso alto). No obstante que el país no pudo restablecer su crédito internacional, se logró contratar un préstamo de 15000000 de dólares con el National City Bank de Nueva York ${ }^{37}$ y negoció anticipos fiscales de compañías petroleras por 10000000 de dólares. Para no recortar más empleos, el gobierno redujo salarios entre 10 y 15\%. Con esta estrategia intentó compensar una caída de ingresos (en 1931) cercana a 75000000 de pesos o $30 \%$ del presupuesto de $1929-1930 .{ }^{38}$ Esta brutal caída era causada por la depresión internacional. Aunque puedan cuestionarse por bajos, los números oficiales ofrecen un panorama de la caída y de la recuperación que, como puede deducirse, no fue milagrosa ni ocurrió en 1933. Incluso en 1934 la recaudación no igualó la de 1930 pese a la devaluación acumulada (véase cuadro 2).

${ }^{36}$ Recaudó 20000000 de pesos y fue protestada por las Cámaras de Comercio, Agrícolas e Industriales. En tono excesivo, Pani la calificaba aún mucho después de "gabela, injusta, absurda y retroactiva, fue más bien un atraco", en Pani, Apuntes, 1951, p. 143. Otros políticos-empresarios nacionalistas, como Almazán, ni siquiera la recuerdan.

${ }^{37}$ Para el empréstito se formó una comisión que vigilaría la ejecución de los fondos, véase Acta 312, 26 de diciembre de 1930, en AHBM.

${ }^{38}$ El presupuesto oficial aprobado en 1931 fue de 299500000 pesos, para ingresos estimados en 300000000 . Al caer estos se ajustó el gasto a 246500000 pesos, pero las recaudaciones caerían debajo de 228000 000; el presupuesto finamente ejercido fue de 231600000 pesos. Hubo también obligaciones insolutas (sin considerar intereses y obligaciones suspendidas o aplazadas), en especial bonos de deudas agrarias y bancarias, así como préstamos del Banco de México que, en total, sumaban 28000 000, véase el informe presidencial del 1 de septiembre de 1932. En octubre de 1932, el Congreso del Partido Nacional Revolucionario ratificó el propósito de equilibrar el presupuesto público. 
CUADRO 2. INGRESOS Y RECAUDACIÓN, 1925-1935 (EN MILLONES DE PESOS)

\begin{tabular}{ccc}
\hline Año & Total ingresos & Total impuestos \\
1925 & 322 & 244 \\
1926 & 309 & 245 \\
1927 & 307 & 229 \\
1928 & 311 & 233 \\
1929 & 322 & 231 \\
1930 & 289 & 234 \\
1931 & 256 & 189 \\
1932 & 212 & 155 \\
1933 & 223 & 163 \\
1934 & 295 & 222 \\
1935 & 313 & 256 \\
\hline
\end{tabular}

Fuente: “Ingresos del Gobierno Federal, 1925-1979”, en INEGI, Estadísticas, 2009.

En las magnitudes traslucen problemas sociales graves pero no debiera olvidarse que la mayoría de la población trabajadora (9500 000 de un total de 16500000 personas) vivía casi autárquicamente con grados de monetarización e integración mercantil muy bajos. Es difícil estimar cifras para el trabajo del campo sobre todo si se atiende el infantil. En ejercicio de contrapunteo cabría estimar "a lo alto" a trabajadores de industrias privadas (minero metalúrgicas, transformación, transportes, comercio, etc.), en cifra menor a 650000 personas en $1929{ }^{39} \mathrm{Si}$ agregáramos empleados del gobierno (ejército incluido) habría, probablemente, una población económicamente activa de 800000 personas; por sustracción se colegirían cerca de 8000000 de personas en el campo. ${ }^{40}$ A mediados de 1930 diversos periódicos aproximaron a 90000 el número de desempleados, cifra que si bien es especulativa no parece disonante con los números más generales. Desde luego, estos números no reflejan los impactos por el regreso de braceros a poblaciones norteñas, ya presionadas por la caída de las exportaciones, cierre de minas, etcétera.

${ }^{39}$ Las cifras las estimamos de Silva, México, 1932.

${ }^{40} \mathrm{El}$ jornal medio de un peón de campo osciló de 0.67 centavos a 1.31 pesos en estados con mayor densidad poblacional; los de menor densidad pagaban de 1.35 a cuatro pesos. Los jornales no se ganaban todo el año -la disminución de haciendas aumentaba el fenómeno-, pero en la cosecha solían aumentar "un poco", véase ibid., pp. 42 y ss. 
Otro indicador son los ingresos de la compañía estatal de Ferrocarriles Nacionales, que avanzaba un programa crucial de reorganización donde se invirtieron cuantiosos recursos en el marco de renegociación de su deuda. ${ }^{41}$ Los problemas de la compañía eran más amplios pero esta crisis condicionó su futuro (véase cuadro 3 ). No es posible revisar todas las respuestas a sus problemas laborales pero se priorizó reducir las horas de trabajo antes que al personal.

Los ferrocarriles no eran el único rubro estatal donde las obligaciones crecían y los ingresos caían. La Dirección de Pensiones erogó 2500000 pesos en 1926 y 5500000 pesos en 1931. A la Comisión Nacional de Irrigación se le cuestionaron proyectos fallidos; la presa Don Martín, que significó más de 20000000 de pesos es sólo un ejemplo. ${ }^{42}$

Otros desajustes venían de combinarse deficiencias productivas con núcleos urbanos en crecimiento y se expresaban en alzas de precios, carestías, coyotaje, etc. El rendimiento por unidad agrícola fue muy bajo en el periodo; en los 18 cultivos más importantes sólo modestamente la caña de azúcar, el haba, la naranja y el trigo incrementaron volúmenes de 1928 a $1930 ; ;^{43}$ pero los naranjeros, como la mayoría de los cultivadores, no ganaron más con mayores esfuerzos. La especulación de precios y el incremento de importaciones (manteca, trigo, maíz, frutas, huevo y ganado, etc.) eran un problema multidimensional cuyas cantidades, vistas en conjunto, no eran menores (cerca de 50000000 de pesos). Pero la caída del producto agrícola ofrece otros ángulos de la crisis; si comparamos en forma abstracta el tamaño de la población con la superficie sembrada (sólo $3 \%$ del territorio) y las necesidades sociales, el margen de recuperación luciría muy amplio, pero la relación de estos factores ocurría en medio de disputas campesinas, políticas agrarias incoherentes que devenían en inseguridad jurídica de la propiedad o sin infraestructura comercial que favoreciese a pequeños productores, etc. Las relaciones de estos fenómenos con la Ley de 1931 se suelen desatender; como otras cuestiones importantes que, a continuación, esperamos esbozar.

${ }^{41}$ Plata, plomo, cobre y zinc redujeron extracciones; mientras el ganado, frutas y legumbres enfrentaban el incremento de los aranceles americanos. El periódico Excélsior, 31 de enero de 1931, reportó la caída de los ingresos ferrocarrileros: en septiembre ingresaron 12600000 pesos, en octubre 11700000 pesos y en noviembre sólo 9600000 pesos.

${ }^{42}$ Otros casos en Anaya, Banco, 2011; otra denuncia en La Prensa, 26 de enero de 1931.

${ }^{43}$ Silva, México, 1932, pp. 13-45. 
Am. Lat. Hist. Econ., año 20, núm. 3, septiembre-diciembre, 2013, pp. 170-209

\section{CUADRO 3. INGRESOS, GASTOS Y COEFICIENTE DE EXPLOTACIÓN DE LOS FERROCARRILES NACIONALES, 1926-1931}

\begin{tabular}{lcccc}
\hline Años & $\begin{array}{c}\text { Ingresos brutos } \\
\text { (pesos) }\end{array}$ & $\begin{array}{c}\text { Gastos } \\
\text { (pesos) }\end{array}$ & $\begin{array}{c}\text { Ingresos netos } \\
\text { (pesos) }\end{array}$ & $\begin{array}{c}\text { Coeficiente de } \\
\text { explotación }\end{array}$ \\
1926 & 112412828 & 103173351 & 9239477 & 91.78 \\
1927 & 111056003 & 104448240 & 6607763 & 94.05 \\
1928 & 112624723 & 99903467 & 12721256 & 88.70 \\
1929 & 112921197 & 91636022 & 21285175 & 81.15 \\
1930 & 107520354 & 93135746 & 14384608 & 86.62 \\
1931 & 8835659 & 73446007 & 14910552 & 83.12 \\
\hline
\end{tabular}

Fuente: “La previsión”, 1932.

\section{LA REFORMA MONETARIA DE 1931 Y SUS CRÍTICOS}

Pani es inconsecuente consigo mismo cuando, en nombre de la estabilidad monetaria, condena la política de su antecesor en 1931 y es injusto cuando lo hace responsable de la desvalorización de $1932 .{ }^{44}$

Es el título de un ensayo que nos ocupa. ${ }^{45}$ Eduardo Turrent, su autor, lo apoya en tres críticos coetáneos: Alberto J. Pani, Miguel Palacios Macedo y Juan Andrew Almazán, el famoso "Camaleón de la Revolución”, cuyas Memorias empleó junto con trabajos de Jaime Gurza y el joven Raúl Ortiz Mena. ${ }^{46}$ El ensayo no advierte que Pani y Almazán ocultaban intereses personales al reprobar la gestión de Montes de Oca, cuyos argumentos -inopinadamente- no fueron contrastados. De Almazán se recogen juicios valorativos y un memorándum "técnico" que le elaboró Palacios; ${ }^{47}$ ambos

${ }^{44}$ Eduardo Suárez, "Más que estabilizar, elevar el ingreso", Excélsior, 11 de mayo de 1955. Suárez fue ministro de Hacienda de 1936 a 1946.

45 Turrent, "Reforma", 2006.

${ }^{46} \mathrm{El}$ resto del aparato crítico son ensayos posteriores no soportados en investigación primaria.

${ }^{47}$ Almazán sostuvo que el memorándum de Palacios causó sorpresa, pero es probable que el efecto fuera distinto pues él integraba el comité intersecretarial que estudió la cuestión monetaria. Véase Acta 296, 26 de octubre de 1930, en AHBM. Así que dispuso al menos de nueve meses para "sorprender" con críticas más oportunas. Sus afinados recuerdos vinieron en un momento curioso: a 28 años de ocurrir "los hechos" (El Universal, 18 de diciembre de 1958) y coincidentemente a unos días de la muerte de Montes de Oca (4 de diciembre de 1958). 
niveles suponen contradicciones que en ocasiones se aclaran y en otras se desatienden.

Francisco Suárez enmarca las reformas con interés didáctico en lo que considera su trasfondo teórico, una pugna de ortodoxos monetarios y desarrollistas. ${ }^{48} \mathrm{Al}$ margen de anotaciones complementarias, para Turrent "la falla fundamental" de la Ley de 1931 fue no considerar "la totalidad de las alternativas de acción abiertas a la autoridad" hacendaria. ${ }^{49}$ Turrent, amplía su tesis de "la falla fundamental":

¿Sordos y desinteresados respecto de los ecos del exterior? Se tiene la impresión de que los autores de la ley monetaria no investigaron suficientemente antecedentes y otras experiencias enriquecedoras mientras preparaban su propuesta. Pero, de preferencia, más que de sordera o desinterés habría que hablar de otras cosas: de cierta miopía intelectual, de un conocimiento parcial sobre la materia, de insuficiente información, de la renuencia a buscar asesoría en una forma más amplia y generosa, de apresuramiento, de un bagaje de conocimientos un tanto anticuados sobre el tema, de cierta insensibilidad ante los tiempos históricos que corrían y también -como se insinúa en los textos de Palacios Macedo- de una buena dosis de dogmatismo y arrogancia profesional. ${ }^{50}$

Esta riqueza de adjetivos contrasta con la evidencia histórica que apunta en sentido contrario. Ya referimos el Congreso de Economía y comisiones intersecretariales donde participaron "los autores", y si vamos al plano axiológico, donde transcurre la cita, debería ser innecesario anotar que Luis Sánchez Pontón -cercano asesor del ministro- comparó las medidas implementadas en 37 países económicamente representativos. Concluyó que 35 redujeron presupuestos; 22 aumentaron impuestos y doce contrataron empréstitos como recurso parcial. ${ }^{51}$ Otros asesores ampliaron información de más casos particulares. Montes de Oca conoció los traba-

${ }^{48}$ Suárez, "Visiones", 2005, y "Desarrollismo", 2006.

${ }^{49}$ Realmente se considera poco la participación de las autoridades bancarias en Turrent, "Reforma", 2006. La censura es extraña pues Montes de Oca fue parte principal de comisiones plurales. Participó en el Congreso referido, mantuvo correspondencia con articulistas especializados; antes, organizó la comisión Sterret-Davis y la Biblioteca Lerdo para impulsar la investigación económica. En la saturación de notas y artículos, la prensa desató un torrente de ideas donde se discutían todas las "panaceas" imaginables. Justo es señalar que hubo editorialistas que pidieron no se publicaran “iMás artículos, no!”, véase Boletín Financiero, 31 de julio de 1931.

${ }^{50}$ Turrent, "Reforma", 2006, p. 269, observa que "la comisión redactora estaba conectada con el mundo". iMenos mal! pero su precisión se corresponde poco con el espíritu literal del ensayo. Critica arrogancia en el montesdioquismo pero olvida el ineficiente nepotismo y alianzas políticas que acompañaron el regreso de Pani.

${ }^{51}$ El Economista, 1 de septiembre de 1931, p. 12. 
jos de Kemmerer en China y le pidió su opinión del proyecto de reforma. ${ }^{52}$ Vale comentar esto pues, irónicamente, algunos rasgos conservadores de la Ley pueden explicarse mejor desde un ángulo opuesto al "parroquialismo". Se aclaran más si se revisa la información internacional de la época, pues -como vimos- hasta cierto punto, se siguió el mainstream.

Para Suárez el "mayor obstáculo" que enfrentó la recuperación fue la política contraccionista seguida "para restablecer el patrón oro formal" ${ }^{53}$ De fondo el punto que destaca es que no había razón para preservarlo. $\mathrm{O}$, ¿qué importancia tenía que fuera el paradigma monetario dominante? No obstante la minucia y al margen de polarizaciones ideológicas de la época, cabe recordar que el final del patrón oro sólo fue resuelto hasta Bretton Woods en 1944. El obstáculo, la obcecación de Montes de Oca, "la expresión más fiel del pensamiento ortodoxo y la que daría lugar a la debacle de 1932" (cuando ya no era ministro), aparece como deus ex machina colmando causas y errores.

Así, para Turrent la reforma falló por omisión y para Suárez por acción. Al ser tan abiertas las causas del fracaso y al ser sus ensayos el paradigma que norma la comprensión de las reformas de 1931 y 1932, resulta pertinente revisar sus debatibles premisas y acentos.

Suárez, a su vez, blande la "ortodoxia" como premisa de su descalificación pero la búsqueda de rechazo, que encuentra sentido en una discusión política, no es convincente en un examen histórico, sobre todo si se erige en reducciones cuestionables. En principio no todos sus significados son pertinentes para evaluar ese contexto. Es sintomático que apenas aluda a la ambigüedad de la época, su riqueza en discusiones, dudas y productos teóricos; por ejemplo, los ensayos de renovación del patrón oro. La Ley de 1931 fue uno de sus ejemplos. Desatiende que la inflación era considerada más nociva que una deflación coyuntural (Keynes dixit) ${ }^{54}$ sin duda, Montes de Oca participaba de esta idea, que acentuó su conocimiento directo de la debacle fiduciaria carrancista y la desgracia alemana de la década de $1920 .^{55} \mathrm{Al}$ margen de este temor existe una brecha importante entre los principios liberales que guiaron su comprensión de los problemas y el fundamentalismo económico que Suárez le atribuye.

\footnotetext{
${ }^{52}$ Kemmerer le correspondió con su 4a. Conferencia Comercial Panamericana, "Estabilización monetaria en América Latina", en CEHMC, fondo Luis Montes de Oca, CMLXXV, doc. 22082.

${ }^{53}$ Suárez, "Desarrollismo", 2006, p. 288. Ya precisamos que fue un patrón sin circulación áurea.

${ }^{54}$ Keynes, Tract, 1923, traducido como Keynes, Breve, 1996, pp. 24 y ss.

${ }^{55}$ Que culminó en la Zwangswirschaft, economía forzada nazi; distinta de la "planificada", Planwirschaft de Hindenburg. Por entonces Montes de Oca era ortodoxo en el sentido de prevenir que la economía se elaborara desde corsés políticos, no en rechazar la intervención. Suárez, "Desarrollismo", 2006, p. 286, asocia hiperinflación alemana y nazismo pero no con su respuesta político económica particular.
} 
Conviene aclarar que en el patrón oro (sin importar la ideología de sus administradores) los déficits del balance de pagos se compensaban elevando tasas de interés (para atraer el oro saliente) y/o esterilizando la oferta monetaria, lo que tendía temporalmente a contraer los precios y la demanda agregada. Es improbable que no se deseara "autonomía" monetaria pero, en 1931, se asumió que no existían medios para sostenerla. ${ }^{56}$ Además, por la inestabilidad internacional de cambios y la competencia de los principales mercados financieros (Londres, Nueva York y París) aún no era prudente apostar sobre una futura moneda de reserva. Al final, la hegemonía favorecería al dólar por las reservas áureas del Tesoro estadunidense y porque Inglaterra salió del patrón oro, pero el desenlace no era claro al iniciar el año 1931. Las tensiones no admitían soluciones ni definiciones fáciles, incluso para intelectuales que lucraron denostando a Montes de Oca de reaccionario. ${ }^{57}$

No obstante, las premisas teóricas de las discusiones monetarias eran importantes. Montes de Oca las asumía con seriedad. En su horizonte intelectual no se inscriben fácilmente las ocurrencias tan características de muchos otros personajes del periodo. Así, premisas de regulación prudencial para la banca de 1931 las repite en 1936 al reformar la emisión y el redescuento en la Ley Orgánica del Banco de México. No tenemos espacio para profundizar en la evolución de su ideario o en su importancia institucional pero -en 1931- le inquietaban el déficit fiscal producido por

${ }^{56}$ Como sucedía internacionalmente, en México se reclamó el proteccionismo comercial como alternativa. Este flanco del debate conduce a otras deliberaciones bien exploradas, véase Riguzzi, Reciprocidad, 2007.

${ }^{57}$ Marte R. Gómez, adversario portesgilista, le atribuyó "muchas de las desgracias que sufre el país", por "haber querido ser campeón de un programa reaccionario", véase su carta a Fernando de la Fuente, 23 de junio de 1931, en Gómez, Vida, 1978, pp. 344-346. Se dolía porque entorpeció el radicalismo corporatista agrario de Portes Gil. Su descalificación venía de su idea de "lo revolucionario" cuyo núcleo era el reparto agrario. Los reaccionarios que lo detenían "serían arrasados" pero, ironías, Gómez entendió que Calles también proponía contenerlo. Otra ironía, a E. Villaseñor, profesor universitario poco afín al agrarismo y subsecretario de Hacienda en el cardenismo, le confesó en enero de 1930: "La política agraria en su aspecto expropiatorio debe liquidarse, naturalmente. En ello hemos estado de acuerdo nosotros [los portesgilistas], pero... las resistencias de los elementos reaccionarios... han sido las únicas que han alargado, perjudicialmente, la resolución de un problema que debió haber quedado liquidado con mucha anticipación. El remedio por lo mismo no es proponer indemnizaciones en efectivo que sobrecargarían el presupuesto con 100000000 de pesos si se quisiera seguir con el mismo tren de actividad que hemos implantado". A lo mejor "el remedio" (que no aclaró) era no pagar (lo que se verificó), pero el recargo ya deterioraba al fisco y activos bancarios, preocupando -con presiones internas y externas- a Montes de Oca. Pani censuró a este suspender el pago de esos bonos sin reparar en la imposibilidad presupuestal de cumplir, véase Pani, Tres, 1941, p. 133. 23 años después, y aun reciente el deceso de Adolfo de la Huerta, Portes Gil relató las "súplicas" de Pani por regresar a Hacienda y las razones de su rechazo, véase "Portes Gil arremete contra Pani", La Prensa, 10 de agosto de 1955 y "Pani, el villano del drama", Hoy, 12 y 13 de agosto de 1955, con los que intentó desmontar también las críticas vertidas en Pani, Problema, 1955. 
la deuda agraria, el abuso político del crédito estatal y la poca eficiencia de los proyectos subsidiados.

Aunque fuera importante debatir ideas en 1931 o 1932, las polémicas eran un asunto relativo y marginal pues la disputa central era -como en 1923, 1927 o 1929 - la de los generales entre sí, en este caso, Plutarco Elías Calles versus Pascual Ortiz Rubio. En el control de las riendas político militares no jugaban, en la economía había ensayos. Sus grupos discutían, diferían pero también convergían. En la reforma de 1931 convergieron más de lo que observa la historiografía canónica. Así, por principio, los asesores de Pani y Montes de Oca fueron casi los mismos; tal es el caso de Fernando de la Fuente y Manuel Gómez Morín quienes diseñaron la Ley y su enmienda, y criticaron ambas. ${ }^{58}$ Entonces las preguntas son ¿cómo clasificarlos?, ¿eran "ortodoxos" o "pre keynesianos"?, ¿de verdad eran muy distintos dos proyectos hechos casi por los mismos autores ${ }^{59}$ Sus resultados variaron, no hay duda; pero exagerar los colores ideológicos y los paradigmas teórico-económicos para encomiar la bondad de políticas contra cíclicas (sin analizar sus circunstancias y efectos finales) no hace más sólida la argumentación aunque le dé fuerza retórica.

Respecto a atribuirle dogmatismo miseano a Montes de Oca, caben varios cuestionamientos. Primero fechar su interés por la obra de Mises, lo que si bien no es fácilmente precisable pudo ocurrir en 1924. En contraste, se puede afirmar que su acercamiento fue más político-filosófico que económico; un indicio lo da su interés por priorizar una traducción de Lippmann.$^{60}$ Por otra parte, si leyó la Teoría del diner $0^{61}$ de Mises, no es claro cuánto lo influyó, qué ideas adoptó ni qué hizo con ellas. Más justo sería señalar que un vistazo superficial de su biblioteca muestra que entonces tenía muchas otras inclinaciones, incluido Keynes, de su A Revision of the Treaty: Being a Sequel to the Economic Consequences of the Peace, que dominaba el ambiente diplomático alemán cuando él era cónsul en Hamburgo, em-

\footnotetext{
${ }^{58}$ Eduardo Suárez, "El Problema", Excélsior, 11 de mayo de 1955, cita el memorándum de Gómez Morín que reclama a Pani la inflación. Fernando de la Fuente, quien vio en Gómez Morín la razón por la que Hacienda se sumió en "la soberbia y la infalibilidad", ya estaba "retirado por completo" de su amigo Pani en mayo de 1932, véase en CEHMC, fondo Luis Montes de Oca, CMLXXV, doc. 23937. Pani agradeció a Gómez Morín y a De la Fuente su cooperación en su enmienda, véase Secretaría, Crisis, 1933, p. 10.

${ }^{59}$ El caso recuerda a un compositor, Aleksandr V. Aleksándrov, que escribió el "casi mismo" opuesto himno (soviético y ruso) pero... en ocasiones distintas.

${ }^{60}$ Montes de Oca publicó primero The Good Society (1937) como Retorno a la libertad en febrero de 1940 gracias a la asistencia de tres colaboradores. Para Mises, Suárez, "Desarrollismo", 2006, p. 290, cita una edición de 1987 que refiere trabajos publicados por Montes de Oca hasta 1952. Hay, por tanto, una anacronía.

${ }^{61}$ Es el más temprano ejemplar de Mises en su biblioteca (Mises, 1924). Es sugerente que no conserve la anterior, Teoría de la moneda, München, Duncker \& Humblot, 1912. J. Cape la tradujo al inglés (Londres, 1934) y Antonio Riaño hizo la primera española en 1936.
} 
pleó la noción de capacidad de pago al renegociar la deuda en 1928-1930, y de su Tract on Monetary Reform pudo compartir, como hemos visto, algunas ideas. ${ }^{62}$ Por esto parece inadecuado calificar de mentalmente estrecho a tan inquieto autodidacta. Después de 1927, Mises publicó otros trabajos que recibieron aún más publicidad dada su crítica al intervencionismo estatal y al socialismo; ${ }^{63}$ por sus fechas de edición se colige que dadas sus actividades no podía estudiarlas. En todo caso, la tesis miseana de que la inflación era la causa crucial del desequilibrio de la balanza de cuentas estaba en franca disonancia con la realidad mexicana y con la mayoría de los análisis producidos. Montes de Oca, quien conocía el problema de la deuda, ${ }^{64}$ no podía aceptar ese argumento. Él no cuestionó el intervencionismo callista y su renuencia al portesgilista se debía a su insostenibilidad financiera (nunca reprochó sus aspectos morales ${ }^{65}$ ) que recargaba el presupuesto cuando decaían los ingresos federales. En la década de 1940, su crítica a la intervención se dirigió al problema de su eficiencia, pero antes y en casos especiales no la rechazó. ¿’Por qué no recordar que Montes de Oca encabezó la colecta nacional para pagar la expropiación petrolera en marzo de 1938? ¿Acaso esta no fue una medida intervencionista?

Es impreciso atribuir gran importancia política a Montes de Oca; la penuria fiscal era tensada por enormes demandas sociales que limitaban su influencia. Gustaba diferenciarse de los políticos (militares y líderes), quienes solían clasificarlo de intelectual o técnico. Ascendió y dependió siempre del clan Calles. Emilio Portes Gil lo ratificó siguiendo acuerdos con Calles luego que crearan el Partido Nacional Revolucionario y sabiendo que no encauzaría cambios hacendarios relevantes. Su sucesor, Pascual Ortiz Rubio, también intentó crear su clientela y la política siguió desmigajándose en acuerdos más complicados y menos creíbles. Con Ortiz, Montes de Oca tenía una relación previa (trabajó con él en Nueva York y Alemania), gozaba de su amistad y confianza pero, como cualquier alto funcionario, seguía informando y consultando a Calles. Esta diarquía se caracterizó por sus crisis ministeriales y legislativas que Calles manejó hábilmente; como en octubre de 1931 Montes de Oca favoreció una solución intermedia, que terminó reforzando al callismo. Calles "fue nombrado"

\footnotetext{
${ }^{62}$ Nos referimos a Keynes, Revision, 1922. Otros dos textos keynesianos de tenor e influencia similares se localizan en su biblioteca, Keynes, Economic, 1920, y Tract, 1923.

${ }^{63}$ Mises, Liberalismus, 1927; Geldwertstabilisierung, 1928; Kritik, 1929, y Ursachen, 1931.

${ }^{64}$ Cabe mencionar que la tesis con que se recibió como contador público, en la Escuela Superior de Comercio, versó sobre las consolidaciones de la deuda pública porfiriana.

${ }^{65}$ Véase "Estudio y resoluciones sobre el problema agrario bajo la administración del C. presidente de la república, ingeniero Pascual Ortiz Rubio", Acuerdos 1-4, México, 1957, en Archivo Particular Pascual Ortiz Rubio (en adelante APPOR).
} 
ministro de Guerra y convocó a "enérgicas resoluciones reconstructivas" ${ }^{66}$ Cobró mayor poder formal pero su credibilidad como jefe de la revolución mermaba; recibía más críticas públicas, empleaba más fuerza para acallarlas y perdía cabezas sin poder renovarlas con mejores personalidades. La lucha política continuó y en enero de 1932 varios miembros del gabinete presidencial que lucían cierta autonomía ante Calles, incluido Montes de Oca, renunciaron. ${ }^{67}$

Para Montes de Oca existía otra causa de desgaste político. Libraba una campaña pública por su negociación de la deuda, que secundaban ex obregonistas, portesgilistas y callistas. ${ }^{68}$ Desde luego, esa campaña tenía su réplica en intrigas políticas. ${ }^{69}$ La campaña tuvo gran eco, apenas menor al de la agitación laboral y agraria. Con viento en contra intentó consensos legislativos, bancarios y empresariales que serían acotados y frágiles. Su renuncia y distorsiones periodísticas apresurarían su olvido. La campaña contribuyó a cebar los males en su figura. ${ }^{70}$ Evocó simplismos en sus acusaciones, como sucedía en Estados Unidos hacia Herbert C. Hoover, quien sería responsable de sus rencillas familiares, del mal tiempo, incluso de la orfandad de los niños de la calle. ${ }^{71}$ Se olvidaba que la Ley, conocida como Plan Calles, era producto de acuerdos políticos amplios y uno de los pocos motivos de unión para callistas y ortizrubistas. La etiqueta pretendía infundir confianza y explica por qué incluso en diciembre de 1931 -en otro clímax de la diarquía- Montes de Oca logró que el Congreso lo sostuviera pese a la oposición de influyentes y vociferantes diputados y senadores

${ }^{66}$ Entonces Montes de Oca compartió la idea antiliberal de "suprimir todo germen de perturbación del orden”, como el producido por el distorsionante sensacionalismo de la prensa en relación con los problemas económicos, en CEHMC, fondo Luis Montes de Oca, CMLXXV, doc. 22225, 19 de octubre de 1931. En un ambiente caldeado por la crisis cristera, la lucha antirreeleccionista, el ascenso del movimiento vasconcelista y la rebelión escobarista, muchos actores políticos tuvieron actitudes de duda, desafío, apoyo y distanciamiento ante el callismo. Montes de Oca lo ejemplifica bien; apoyó pero también renunció, véase CEHMC, fondo Luis Montes de Oca, CMLXXV, doc. 22190, 14 de octubre de 1931.

${ }^{67}$ Él salió abruptamente del país, Genaro Estrada, Aarón Saénz y Gustavo Serrano también fueron renunciados. Almazán conocía "las intrigas descaradas de los callistas" (véase El Universal, 8 de diciembre de 1958) que sufrió al reformarse "su" Ley de Comunicaciones. Su encono contra Calles venía porque la Secretaría de Comunicaciones le canceló contratos para construir caminos.

${ }^{68}$ Anaya, "Convenios", 2001.

${ }^{69} \mathrm{El}$ papel que desempeñó Pani desde 1927 fue sesgado y contradictorio, como puede verse en Archivo Calles-Torreblanca (en adelante ACT), exp. 162/197, inv. 648, gaveta 40, o en su correspondencia inédita con Marte R. Gómez. En la última carta -sí editada- que Gómez le envió trasluce su molestia por su actuación similar pero ahora contra él, luego de sucederlo en la Secretaría de Hacienda. cumplió.

${ }^{70}$ Fue común que la prensa atribuyera la crisis a la renegociación aunque su acuerdo no se

${ }^{71}$ McElvaine, Great, 1993, p. 52, muestra un Hoover más activo ante la crisis de lo que suele creerse. México formó la Comisión Reorganizadora de la Administración Pública presidida por Puig Cassauranc, para observar las respuestas en Washington. 
como Flavio Manlio Altamirano. Lo que no venció fueron las contradicciones de Calles, quien sostenía el Plan sin ayudar a consolidarlo, buscaba cosechar dividendos sin pagarlos. Lo prueba su ambiguo desempeño en el Banco de México (como muestra, su cuantioso crédito para el ingenio El Mante en medio de la crisis, por el que Gómez Morín renunció a la presidencia de su Consejo de Administración ${ }^{72}$ ), el predominio de su clan en el gabinete durante 1932 (ratificado con su ascenso al Ministerio de Guerra), la renuncia de Ortiz Rubio y la designación de su subsecretario, Abelardo L. Rodríguez, como presidente interino.

Suárez y Turrent coinciden en que la situación monetaria y cambiaria era empeorada por la desaceleración económica mundial y la grave crisis política interna. Pero sus alusiones no aclaran por qué se relevó a Montes de Oca. Turrent sugiere que se analizó la reforma al defenestrarlo, su fracaso fue "el Waterloo de sus artífices". ${ }^{73}$ Por lo demás tal análisis parecía natural o, al menos, aconsejable y deseable. Pero si ex post esto podría parecer obvio, ex ante no tuvo mayor valor. ${ }^{74}$ Más aún, si diéramos por buenos (o al menos por mejores) los testimonios de actores directos que preguntaron a Calles sus razones para defenestrarlo, se podría leer una historia distinta que merecería igual o mayor atención que especulaciones posteriores. A decir de Freyssinier Morín, para Calles los ambiguos resultados de la reforma monetaria sólo fueron una entre otras causas, siendo más importantes sus "dilaciones burocráticas", no acceder a sus indicaciones y sugerencias respecto al Banco de México y "querer acabar con este" -por cierto, Calles presidía su Consejo y estuvo de acuerdo en formar la Junta Central Bancaria-, expedir la nueva ley de licores sin su anuencia e intentar acabar con el Partido Nacional Revolucionario, ${ }^{75}$ etc. Podemos descreer que el jefe máximo tuviese esos motivos y que Montes de Oca los creyera. ¿Por qué no explicar su desencuentro en su combate a las corruptelas del general Saturnino Cedillo o de los inspectores de alcoholes y aduanas? Su rele-

${ }^{72}$ Anaya, "Mante", 2012.

${ }^{73}$ Turrent, "Reforma", 2006, p. 278. Y como de tres muy importantes dos participaron en la enmienda de 1932, resulta que sólo Montes de Oca tuvo su Waterloo.

${ }^{74}$ Ningún crítico observa que Montes de Oca renunció (renuncia aceptada durante una semana) en la primer crisis ministerial (14 de octubre de 1931); es decir, antes de que se presentaran los efectos por los que se suelen explicar su remoción.

${ }^{75}$ Freyssinier era su contador en El Mante y en su hacienda Santa Bárbara. Él describió a Montes de Oca "los cuentos" principales, véase CEHMC, fondo Luis Montes de Oca, CMLXXV, doc. 23531, 15 de febrero de 1932. Claro que el Partido Nacional Revolucionario lucía desgastado, pero Montes de Oca instrumentó los acuerdos -febrero de 1931- de Plutarco Elías Calles, Ortiz Rubio y Lázaro Cárdenas (presidente del Partido Nacional Revolucionario) para descontar un día de salario en meses de 31 días a empleados federales para sostenerlo. Véase CEHMC, fondo Luis Montes de Oca, CMLXXV, doc. 20853. Pani elevó el descuento de 1.65 a 1.80\% en la segunda quincena de febrero. Sobre la peregrina idea de desaparecer el Banco de México, véase Anaya, Banco, 2011. 
vo, ocurrido en el marco de otra crisis ministerial que realineó fuerzas y coaliciones políticas, obedeció más a la disputa por el control del aparato gubernamental y a las animosidades de los intereses afectados que a una valoración razonada de lo alcanzado y lo erróneo. Prevaleció el frenesí de una disputa política cuyos perfiles se decantaron después de las convenciones del Partido Nacional Revolucionario en 1932 y 1933, del fracaso de las Conferencias de Londres y de que Calles empujara la idea de planificar sexenalmente los programas gubernamentales como método de control de los aspirantes presidenciales.

Allende maquiavelismos, Calles sabía -por cualquier prognosis razonable- que la primera etapa de la reforma sería la más dolorosa, que causas estructurales deterioraban la economía y que la caída de precios y mayores barreras arancelarias en Estados Unidos dificultaban la recuperación interna. En marzo de 1932 declaró a la prensa internacional que los problemas mexicanos sólo "reflejaban la crisis mundial":

estoy convencido que la crisis por la cual los países llamados capitalistas están atravesando, puede llevarlos a una catástrofe, a menos que aquellos que tienen a su cargo los destinos de varias naciones arrojen su apatía y falta de resolución y se unan para producir métodos adecuados de cooperación económica antes de que sea demasiado tarde, es decir, antes que los millones de hombres que están agobiados por el sufrimiento intenten cambiar la situación por medios violentos. ${ }^{76}$

Calles lamentó que Estados Unidos concentrara "más de la mitad del oro del mundo", padeciera la mayor desocupación de su historia y no otorgara créditos internacionales. E insistió en que la base de la recuperación era la solidez de la confianza, por cierto, erosionada por los repartos portesgilistas ${ }^{77}$ la agitación de la Ley laboral, la campaña contra la negociación de la deuda y, a comienzos de 1932, por las intrigas para sustituir a Ortiz Rubio.

${ }^{76}$ El Economista, 1 de marzo de 1932, p. 12, reproduce la entrevista de E. J. Bing, gerente de la sección europea continental de la United Press.

${ }^{77}$ En reuniones ministeriales Montes de Oca destacó la importancia de los derechos de propiedad para ejidos y haciendas y la ridícula aportación fiscal de la "cédula agraria", 200000 pesos, menos de 1\% del impuesto sobre la renta, de 20000000 a 22000000 de pesos, véase "Estudio y resoluciones sobre el problema agrario bajo la administración del C. presidente de la república, ingeniero Pascual Ortiz Rubio”, Acuerdos 1-4, México, 1957, en APPOR, p. 49. 


\section{SECUELAS DE LA REFORMA Y SU ENMIENDA}

Estudiar los múltiples impactos económicos de la crisis y cómo fueron atendidos por sus parciales "remedios" monetarios excede los alcances de este artículo; nos limitamos a seguir algunas secuelas. En principio, como ya advertimos, no es plausible que Calles u Ortiz buscaran cambios radicales de política económica con la salida de Montes de Oca. ${ }^{78}$ Pani estudió seis semanas los problemas pero, irónicamente su decisión tuvo tintes de precipitación. ${ }^{79}$ Al final sólo alteró dos artículos. ${ }^{80}$ En síntesis, atacó la iliquidez y abandonó el proyecto de estabilizar el peso para reordenar el crecimiento económico y del mercado financiero. Adoptó una ruta popular pero abrió las del desconcierto y los desequilibrios futuros.

El cambio más inmediato fue administrativo, regularizó los pagos a los empleados federales con fondos de la Tesorería. ${ }^{81}$ El pago de dos quincenas atrasadas antes de Semana Santa motivó a la burocracia a vacacionar fuera de la ciudad de México; con ella salieron de 8000000 a 10000000 de pesos que lloró lastimeramente el comercio citadino, evidenciando su hipersensibilidad a cualquier ajuste. En todo caso, el evento provocó más desconfianza hacia el gobierno de Ortiz Rubio. ${ }^{82}$

La segunda medida fue acuñar pesos plata ${ }^{83}$ (aprovechando el ciclo de nueva confianza que la política estabilizadora y el "giro inglés" dieron a su

${ }^{78}$ Calles autorizó aún en 1933 que se publicara una entrevista suya sobre la rehabilitación monetaria de la plata. Aunque ahí Elías Calles (Rehabilitación, 1933, p. 11) también confesó: "me parece inútil entrar en detalles respecto a la forma en que deba hacerse la rehabilitación".

${ }^{79}$ Gómez Morín se opuso a la idea de dar a la acuñación el estatus de propósito esencial que le concedían Pani, Fernando de la Fuente y el nuevo jefe del Departamento de Crédito, Uriel Navarro. Para él, como para Montes de Oca, la acuñación no era un paso fundamental o previo a la realización de un programa económico (que en 1931 fue rehabilitar el valor del peso y mejorar los términos de intercambio), sino su corolario. Sus ideas más puntuales se expusieron en su memorándum del 7 de marzo de 1932, que al parecer motivó a Pani a apresurar la publicación de su enmienda, Del Cueto, "El memorándum", Hoy, 20 de agosto de 1955, recoge esa sugerente hipótesis.

${ }^{80}$ Pani exageró los cambios que Gómez Morín políticamente conceptuó como segunda fase de la Ley. Turrent, "Reforma", 2006, p. 262, observa que Palacios Macedo propuso certificados de depósito plata como alternativa para reducir la onerosidad de la moneda plata.

${ }^{81}$ Montes de Oca apuntó que los 12000000 de pesos que encontró Pani ahí eran un pago de deuda gubernamental con el Banco de México por emisión de billetes, véase en CEHMC, fondo Luis Montes de Oca, CMLXXV, doc. 23880, 27 de abril de 1932. Eran parte de las deudas insolutas del presupuesto de 1931. Además de cuentas dobles, la expansión fiduciaria tendría bases endebles.

${ }^{82}$ Turrent, "Reforma", 2006, p. 267. Pani minó la viabilidad de ese gobierno. Su aproximación a Calles ocurrió al oponerse a la renegociación de la deuda. Antes, no criticó la falta de instrumentos de cambio como causa de la crisis.

${ }^{83}$ Pani no aclaró bien los montos acuñados, pero hacia marzo-junio es probable que oscilaran en 5000000 de pesos. Aprovechó la diferencia contra su valor metálico, así que si por peso acuñado obtenía un excedente (dependiendo del tipo de cambio y del precio de compra del metal) de 55 a 65 centavos, podría pensarse que se obtuvieron 7500000 pesos. Y si en total acuñó 
cotización) e imprimir billetes. Lo último, por cierto, se aprobó al finalizar el año 1931 para el presupuesto de 1932. Hacienda anunció las nuevas emisiones los primeros días de enero $;^{84}$ se respaldarían en 5000000 de dólares que custodiaba el Banco Nacional de México. Pero los cuidados del retardado programa de emisión se abandonaron. Esto sucedió porque la enmienda disolvió la Junta Central Bancaria y relajó las reglas para aplicar el redescuento que se basaría, sobre todo, en operaciones pignoraticias. ${ }^{85}$ El postrero efecto de dichas desregulaciones se dejó a un lado mientras corría la propaganda anunciando la recuperación y las bondades de la abundancia de dinero.

La Ley avanzó en contener la especulación bajo el principio de desmonetizar el oro (eliminar su canje por dinero), ${ }^{86}$ pero no podía desaparecer su función de moneda de reserva. También la contuvo obligando el pago de deudas oro en plata, aboliendo su mal cumplida función de moneda de apoyo y al prohibir que circularan monedas extranjeras. A dos meses de aplicarse la reforma, la especulación parecía contenida por estas medidas y por factores externos que reanimaron la plata. En paralelo se contuvo el retiro de depósitos (osciló de 20000000 a 25000000 de pesos), aunque el daño mayor era anterior; en enero de 1931 los depósitos sumaban 174000000 de pesos y en julio apenas $115000000 .{ }^{87}$ Como la banca comercial trabajaba con dinero de depositantes, los flujos de sus préstamos seguían el ritmo de los depósitos y, claro, una base de 95000000 o 90000000 de fondos prestables no podía reactivar la economía a niveles de 1930. Tampoco podrían haberla dinamizado otros 25000000 de pesos, pues no era sólo un problema de fondos prestables, sino de su colocación y su retorno. Además, la banca extremaba cautelas, pues, comprensiblemente, crecía la morosidad; las razones de la clientela eran muchas pero

72000000 de pesos con plata valuada en 28 centavos la onza, entonces osciló en 44000000 el ingreso extra que permitió nivelar presupuestos y, parcialmente, financiar su política contracíclica.

${ }^{84}$ Véase Excélsior, 5 y 7 de enero de 1932. Fondo relacionado con complicaciones en la negociación de la deuda.

${ }^{85}$ Incluso cuando contradijeron la ley que los reglamentaba se ajustaron interpretaciones para facilitarla, véase Acta 429, 24 de agosto de 1932, en AHBM. En todo caso la expansión fiduciaria no tenía correlato en incrementos industriales o comerciales, estancados por la débil condición del mercado interno y el consumo.

${ }^{86}$ A saber, billetes del Banco de México, monedas de un peso plata (bajo el cuño de la Ley del 27 de octubre de 1919), fraccionarias de plata de diez, 20 y 50 centavos (creadas por las leyes de 25 de marzo de 1905, 25 de abril de 1914, 27 de octubre de 1919 y 29 de abril de 1927) con poder liberatorio de 20 pesos y fraccionarias de bronce de uno, dos y cinco centavos (con poder liberatorio de hasta dos pesos).

${ }^{87}$ Del 31 de julio al 31 de agosto, los depósitos a la vista bajaron de 116000000 a 96000000 de pesos y permanecerían sobre esta cifra con oscilaciones de 4000000 hasta marzo de 1932 que subieron a 105000 000. En mayo de 1932 sumaban 111000 000; no regresaron su base pese a las nuevas emisiones, véase El Economista, 18 de agosto de 1932. Pani logró el control de este periódico unos meses antes. 
los efectos por el congelamiento de su cartera se reducían a la quiebra. La Ley no solucionó las tensiones entre la banca y sus clientes; la enmienda las aligeró pero al costo de desregular las operaciones de redescuento y elevar el riesgo bancario. ${ }^{88}$

En otra esquina financiera, las casas de cambio se opusieron a la Ley; pero no es de extrañarse pues era uno de sus blancos. Propagaron rumores que en algo influyeron al mercado capitalino pero su época dorada acababa. No hay duda de que la Ley avanzó en liquidar este importante núcleo del "coyotaje" cuya participación en las corridas bancarias de inicios y mediados de la década de 1920 fue muy importante.

Otro aspecto relevante de la conversión de deudas áureas fue su impacto fiscal. Fue un símil de un impuesto retroactivo que castigó la especulación al abaratar transacciones. Como todo impuesto tuvo una reacción. Los afectados lo rechazaron iniciando procesos judiciales, retiros y azuzando rumores que alentaron corridas bancarias pequeñas en Mérida y ciudades del norte. ${ }^{89}$ Sobre las medidas contra la especulación, cabe preguntar ¿̇es adecuado calificarlas de ortodoxas? La historiografía canónica, que ha regateado los fines y caracterización de la reforma, irónicamente ha olvidado a importantes azuzadores de incertidumbre, entre estos, católicos, militares y ex porfirianos que sostenían periódicos amarillistas. ${ }^{90} \mathrm{O}$ a Luis Gallopin, Lionel Dalkowitz, Wilbur Bates, entre otros, que perseguían lucros desde sus campañas contra la renegociación de la deuda. ${ }^{91}$

En las vacilaciones de la crisis, la Ley se debilitó al incumplirse la acordada "unidad de acción". Al final sólo el Banco de México, el de Transportes, el de Londres y México y el del Trabajo devolvieron depósitos oro; los extranjeros, mejor equipados para cumplir, no lo hicieron pese a que la obligatoriedad se limitó a 30\% del depósito. ${ }^{92}$ Depositantes, especuladores, rentistas y capitalistas encontraron que la banca extranjera no siempre era mejor que la nacional. Las sucursales extranjeras que lucraron especulando contra el peso mientras pregonaban la seguridad de sus matrices, ahora

${ }^{88}$ En junio de 1932, la prensa especializada la calificaba de "desastrosa política de crédito". El Banco de México revisó con laxitud esos casos, véase Acta 422, 13 de julio de 1932, en AHBM, para sus efectos en este, véase Anaya, Banco, 2011.

${ }^{89}$ Véase la señera reacción del banco más grande, el Banco Nacional de México, en Trigueros, Devolución, 1934. Gómez Morín y un auditor especial informaron al jefe de Hacienda en Gómez Palacio, Durango, alzas de precios y desconfianza hacia bancos "por maniobras de especulación", pues de la Ley se deberían seguir "resultados inversos", en CEHMC, fondo Luis Montes de Oca, CMLXXV, doc. 21511.

${ }^{90}$ Destacaban los periódicos Omega, El País, La Jeringa y El Mexicanista.

${ }^{91}$ Anaya, "Convenios", 2001.

${ }^{92}$ Véase la tercera disposición transitoria de la ley. La ley eximió también al Banco de México de la obligación de cumplir con la Ley del 27 de octubre de 1919 de cambiar cada peso de moneda fiduciaria por 75 centigramos de oro fino, pues ahora esa conversión se reducía a 30 por ciento. 
declaraban que sus valores eran mexicanos y que los pequeños capitales de sus filiales eran independientes de las arcas de sus matrices. El Banco Nacional de México declaró que devolvería sus depósitos de ahorros aunque no mencionó sus considerables depósitos en cuentas de cheques. Pero no sólo lo mejor resultó peor, además, en su breve vida la Junta Central Bancaria operó sin eficiencia y no obligó para que la norma se cumpliera. La enmienda disolvió esta Junta Central sin evaluar su actuación. Su final facilitó a la banca evadir la norma y, sobre todo, filtrar el descuento de créditos inmovilizados hacia el Banco de México. Esto pudo ser posible porque también ganó influencia en su seno al sustituirse a Alberto Mascareñas, su cuestionado primer director, por Agustín Rodríguez, un banquero afín a las entidades reguladas.

Un área más polémica fue la utilidad del nuevo punto de equilibrio del peso; 2.60 pesos por dólar. El punto lucía alto, pero cabe anotar que la Junta Central Bancaria revisaba la idea de establecer paridades móviles. En tal paridad, las autoridades parecían ratificar sus ideas sobre la relativa estabilidad de la moneda plata y existiendo en curso campañas internacionales para rehabilitar el metal se propiciaba su revaluación. No sobra recordar que analistas serios pensaron que el punto de equilibrio se situaría en 2.50 unidades. ${ }^{93}$ Adicionalmente, si se toma como índice la paridad de 2.06 pesos oro, de mayo de 1928, el nuevo equilibrio asumía una devaluación de $26 \%$. Lo que para la época no era menor (considerando además que la crisis deprimía precios) y de ninguna manera podría considerarse una restauración de paridad. Sin embargo, en el escenario de una industria deficiente y cayendo el producto agrícola, un peso caro favorecía las importaciones.

Suele desdeñarse la estabilidad de finales de 1931 pero frenó la depreciación del peso, controló su especulación y -rasgo pedagógico- mostró que el valor nominal del peso no coincidía con el intrínseco, lo que abonó a la "repentina" aceptación fiduciaria de 1932. Por lo demás, la abundancia de dinero que trajo la enmienda contribuyó a formar un proceso inflacionario: en mayo de 1932 el peso bajó de 3 a 3.23 por dólar y en junio rayaba las cuatro unidades por dólar. ${ }^{94}$ El equilibrio se ubicó 38\% arriba del punto alcanzado a finales de 1931 y el entorno se invirtió al dar prioridad a la expansión monetaria sobre la reorganización económica. Como antes, había fuentes de desconfianza que no pueden asociarse directamente a la enmienda de 1932, como las leyes de expropiación de Michoacán,

${ }^{93}$ Véase nota 20.

${ }^{94}$ Descontento e irónico por el despojo de su periódico (El Economista) a manos de Pani y Elías Calles, Francisco Borja Bolado llamaba al Banco de México "el banco único de acuñaciones ilimitadas y emisiones fantásticas”. CEHMC, fondo Luis Montes de Oca, CMLXXV, doc. 23923, 3 de mayo de 1932. 
Hidalgo y Veracruz que coinciden con la mayor inestabilidad. Entre tanto, declarativamente Pani evitaba la inflación en medio de críticas a la recuperación que se calificó de "enfermiza". Años después aún sostenía que la deflación ocurrió entre 1927 y 1932, que su regreso significó estabilidad con progreso y que después de 1936 vino la era de la inflación con devaluaciones. Pese a que su periodización fue tempranamente rechazada, incluso por sus ex colaboradores, como Eduardo Suárez, sus premisas han dominado la historiografía contemporánea.

En 1931 se subestimaron los efectos de la falta de liquidez y en 1932 los de su exceso. Era cierto que la Ley no contraía la moneda, sino que no tendía a aumentarla, ${ }^{95}$ pero esta sutil diferencia fue irrelevante como lo era para cualquier negocio distinguir entre sus problemas de solvencia y los de iliquidez. Sin crédito, el problema del circulante pareció mayor; entre ambos había un vínculo que debilitó la reforma. Antes de la Ley se estimaba una circulación de 200000000 de pesos plata y 50 de oro; por supuesto que el oro no servía en las transacciones comunes y en este aspecto su retiro del stock no tuvo importancia, pero sí la tuvo en materia crediticia, pues era la base del crédito bancario y al desmonetizarlo desapareció. Plausiblemente esta circunstancia motivó más cautela en los bancos e inequívocamente significó menos crédito en el mercado. En la Ley traslucía una posición crítica de la Secretaría de Hacienda al desempeño del Banco de México: el control de la emisión la evidenciaba. Con su organismo paralelo, la Junta Central Bancaria, se previó evitar presiones para aceptar papeles comerciales inseguros, con los subsecuentes riesgos morales y fiscales. Fue en este marco y en el interés de sanearlo que se definió la aceptación voluntaria de sus billetes. La medida, de tinte liberal, procedía cautamente por las experiencias recientes de rechazo público al papel moneda, por el interés de controlar la masa monetaria y por guardar congruencia con el artículo transitorio que obligaba a la banca comercial a pagar en oro 30\% de los depósitos (cuyo cumplimiento se esquivó) y del que se esperaban reflujos al mercado. Claro, de esto poco sabía el público que sufría desempleo y carestías.

La sobre atención dada a los traspiés del billete ha oscurecido la función de la moneda fraccionaria que pese a ser "pequeña" no llegó "hasta abajo". En este punto ni la Ley ni su enmienda tuvieron avances significativos. Pani multiplicó las monedas de un peso pero los jornales solían ser menores a esta unidad; siendo alta era inadecuada para favorecer el

\footnotetext{
${ }^{95}$ Hubo intervenciones anteriores para retirar excedentes de plata. Luego de la ley las acciones se orientaron a vender monedas antiguas para reacuñaciones, véase Acta 367, 19 de agosto de 1931, en AHBM, el cambio fue de 3000000 de pesos. El 30 de septiembre, Acta 373, en AHBM, el monto de monedas antiguas y metales amonedados por el Banco de México se redujo; el primer y más fuerte costo del ajuste de la moneda plata se comenzaba a saldar.
} 
consumo popular. ${ }^{96}$ De haber funcionado bien la moneda menuda entre la población humilde (que incluso extrañó las monedas de níquel) probablemente habría aumentado su consumo de bienes comerciales y contribuido a liberar pequeños atesoramientos ganando fuerza para reactivar los mercados. Entonces, la retención monetaria obedecía a la falta de billetes, pero también a la inadecuación del peso para transacciones pequeñas y al bajo grado de penetración de la moneda menuda; por cierto, la fraccionaria más baja fue poco acuñada y sus costos de flete eran semejantes a unidades más altas. El intríngulis no se resolvía fácilmente. A diferencia de Gresham, el pueblo bajo no podía diferenciar la moneda mala: ċera la repudiada de papel o la de vellón? ¿Era la inconvertible o la usada por abarroteros para expoliarlos? Con frecuencia olvidamos que en la atrasada evolución monetaria mexicana habían diferencias socioculturales al usar el dinero: los grupos medios y altos capitalizaban especulando mientras los bajos lo preservaban atesorándolo. Y esto dificultaba a la moneda fraccionaria salir "de abajo". ${ }^{97}$

\section{CONCLUSiOnes}

La reforma de 1931 fue el tercer intento del Estado mexicano por crear una moneda con respaldo efectivo en un concierto internacional que depositó en el oro la confianza de sus intercambios. En 1905 el ensayo pareció auspicioso y sí acuñó monedas áureas. En 1918 pareció un recurso para corregir el desorden de las emisiones fiduciarias de la revolución. En 1931 la reorganización propuso al patrón oro como un respaldo teórico pero declaró ilegal su circulación, pues se entendía que el último respaldo estaba en la recuperación de la economía, en el mejoramiento de los términos de intercambio con el exterior y en la posibilidad de constituir reservas nacionales con las cuales atenuar los altibajos del mercado. Aunque nominalmente existía un Banco Central y consensos con la banca comercial para apoyar la rehabilitación del peso, el Banco de México tuvo un papel subordinado e ineficiente y la banca privada no cumplió acuerdos previos e incluso se amparó para evadir la Ley.

\footnotetext{
${ }^{96}$ Se comprendía que subsistiera la realidad de las pseudomonedas. El fenómeno del Soconusco, Chiapas, donde se pagaba con monedas de aluminio, no parece haber sido excepcional. Véase La Prensa, 8 de febrero de 1932.

${ }^{97}$ En esta coyuntura, cuando salió en lugar de ayudar, perjudicó. El anuncio de nuevas monedas legales significó que las monedas de níquel de cinco centavos salieran de la circulación sin reemplazo evidente, véase El Universal, 24 de septiembre de 1931. Al cambiarlas se descontaba la mitad de su valor; lo más alto que se pagaron fue a cuatro centavos.
} 
A la confusión de los lazos que separan y unen a la Ley de 1931 con su enmienda de 1932 contribuyó incluso un dicho de uno de sus autores principales, Gómez Morín, quien conceptuó esta como una segunda etapa de la reforma. En realidad no lo fue: de haberlo sido habría sido consecuente con ella y esto no ocurrió. La enmienda invirtió prioridades y trastocó objetivos.

La Ley introdujo elementos pragmáticos y heterodoxos en un planteamiento ortodoxo. Como en la mayoría de los países, el gobierno tuvo que aceptar reducir el presupuesto (que mitigó al límite de sus posibilidades), técnicamente no aumentó impuestos (y ensayó reducciones), contrató un empréstito (casi irrelevante), castigó la especulación, pero subestimó la falta de liquidez de una economía con muchos desarreglos estructurales.

La brevedad de la experiencia de 1931 torna difícil evaluarla y compararla. Países con importantes déficits comerciales como Holanda sostuvieron políticas estabilizadoras con éxito pero actuaron consistentemente. Los reformadores creían que el patrón oro subsistiría pero no creían en que funcionara rígida o automáticamente, y esto se entrevé en los tintes heterodoxos de su Ley. Como otros estudiosos de la época adolecieron de problemas de percepción. En el bosque no puede verse el bosque y en una aparente ortodoxia áurea lucía más difícil encontrar salida a la crisis nacional, como lo criticó publicitariamente la enmienda, con el lema del "regreso nacionalista de la plata". Como sucedía a los revolucionarios con el Estado, la degradación del patrón oro tiró cimientos del antiguo orden pero fue incapaz de crear, sobre bases nuevas, un sistema eficaz. En tesitura semejante, no hay evidencias claras e incuestionables de que la enmienda de 1932 procediera de un análisis riguroso y exhaustivo de la Ley, corrigió la falta de liquidez pero disolvió sus avances regulatorios.

Cuando el esfuerzo delineaba estabilidad sobrevino el cambio de jinete y de caballo. Ofrecimos motivos plausibles para aclarar este cambio sin estrecharlos a la reducción del canon historiográfico. Reducción que deriva de su tendencia a personalizar, forzar premisas y convicciones, en parte por el desequilibrio de fuentes que normaron su criterio. Positivamente nos recuerdan que no es posible desarrollar nuevas concepciones sin recurrir a la polémica.

Su crítica acentúa el problema real de la falta de instrumentos moneta$\operatorname{rios}^{98}$ pero poco atiende el de la falta de crédito que fue importante y que fue blanco de la reforma o el de la moneda menuda que la reforma omitió.

\footnotetext{
${ }^{98}$ Es difícil aceptar que el problema central era haber caído en una trampa de liquidez, como sugeriría Pani. Su dimensión se evidenciaba en la hipersensibilidad del mercado ante pequeños montos (como ocurrió en la capital de México en marzo de 1932), pero las estacionalidades y la mala circulación la ocultaban.
} 
La restricción crediticia obedecía a problemas fundamentales larvados durante décadas e incluía la cuestionada actuación de la banca comercial en la coyuntura. La Ley de 1931 no dispuso soluciones rápidas a la restricción crediticia, pero la autoridad hacendaria buscó evitarla. Fracasó en su intento: ni el mercado ni la banca podían reaccionar espontánea y sanamente. No podían ofrecer algo que no tenían: no tenían buen papel que descontar, ni reglas adecuadas para redescontarlo. En 1932 la mayoría de los descuentos disponibles trasladó riesgos a la banca comercial y al Banco Central.

El problema de las reservas preocupó a las autoridades. Tenía malos antecedentes ${ }^{99}$ que se intentaron resolver con un patrón oro heterodoxo asociado a un concepto de dinero clásico. La Ley señaló que "para asegurar la estabilidad del peso limitaría el stock a las necesidades del mercado" hasta constituir la reserva. Pero esto sucedía en un mercado deprimido, así que el principio de lograr una estabilidad donde "el mismo número de objetos y servicios materia del comercio social pueda canjearse por la misma cantidad de monedas existentes" sólo podía constatar la contracción. Bajo tal principio se confundieron equilibrio y rigidez. El patrón oro tendía a un equilibrio "a la baja" mientras que el dinero clásico requería uno "a la alta": pronto sería claro que 200000000 de pesos plata no satisfacían el comercio social del país.

El shock externo fue súbito y dramático: vapuleó a la estancada economía. La caída de ingresos fiscales fue peor a cualquier pronóstico de la época. En tal escenario era ineludible que el ajuste tuviera elementos "pro cíclicos", que el canon historiográfico atribuye a "errores de concepción" olvidando -simultáneamente- que los reformadores intentaron evadir sus efectos más regresivos. El canon también olvida que la política de equilibrio presupuestal siguió siendo acuerdo oficial del partido gobernante. Desde aquí podría verse como un falso dilema la pregunta ¿qué era mejor: sostener el nivel de cambios o el de precios? Tal interrogante parecía ser el núcleo que diferenciaba la reforma de su enmienda, pero la solución se hipostasió, fue ficticia; el nivel de precios se corrigió enfermizamente y se abandonó cualquier política real de estabilidad.

${ }^{99}$ La falta de reservas oro que compensaran el valor metálico y nominal de la moneda fiduciaria se señaló como causa del desajuste. En 1919 se acuñaron casi 200000000 de pesos plata sin garantía. En 1923 Pani volvió a acuñar y en 1927 Montes de Oca constataba que el stock era superior a las necesidades. En 1931 se estimaba que la masa monetaria se reducía a 33\% de su valor nominal. Claro, como vellón esto no era cuestionable, pero para su regla de conversión (20 pesos) e intercambio oro sólo servía por el valor que contenía. En este punto la plata no cumplió su función como moneda de apoyo. ¿Qué habría sucedido si se hubiese respetado el límite del poder liberatorio? ¿Y qué si, como estaba normado, se hubiese consolidado un fondo regulador de la moneda? No lo sabemos pero es plausible suponer que su ritmo de depreciación y los ataques especulativos no hubiesen sido tan marcados. 
Antes de la crisis la banca privada y la estatal tuvieron un comportamiento mediocre; la privada pudo prestar y no lo hizo, la estatal lo hizo pero sin mayor impacto, sus caudales eran escasos y sus criterios de asignación más políticos que de eficiencia. En la crisis, la privada no apoyó la reforma, sus renuencias, resistencias legales y su explicable comportamiento conservador crearon más incertidumbre que aliento a la economía. La estatal poco pudo hacer y el Banco de México, reducido en funciones, pudo hacer menos. La larga data del crédito contraído también se debía al aumento de adeudos y moratorias privados y públicos; como anotamos, en 1929 nuevos bonos agrarios sin fondeo renovaron el problema y tensaron las decisiones del gobierno.

En la reforma de 1931 subyacía el intento de restaurar el crédito internacional, estimular inversiones con garantías de ley ${ }^{100}$ y orientar las finanzas con moralidad administrativa. Se quiso hacer de la necesidad virtud y se renunció a reaccionar creando dinero rápidamente. El intento se abandonó en medio de la disputa por controlar el Estado, así que más bien catalizó vacíos de autoridad y corruptelas que, como menor defecto, añadieron ineficiencia al gobierno.

La guerra siempre ha influenciado la evolución monetaria. Por su causa, las casas de moneda cambian de manos, cambiando acuñaciones, denominaciones y leyes. México ejemplificó bien cómo la violencia combinada con una economía débil podía tener malas manifestaciones monetarias durante plazos largos; en la sima de la depresión internacional, los fundamentos económicos evidenciaron su debilidad. Entonces, el líder máximo de la revolución, Calles, prestó su apellido al Plan pero, en los hechos, le escamoteó su apoyo. Su fracaso acompañó el triunfo de su fuerza política. Esta aparente ironía no debiera verse como asunto menor, pues se ha probado bien su ambigua preocupación por las instituciones. ${ }^{101}$ Una suspicacia similar merece la publicitada y "milagrosa" recuperación que habría seguido a la enmienda de 1932.

\section{Fuentes CONSULTADAS}

\section{Archivos}

ACT Archivo Calles-Torreblanca, ciudad de México, México.

Ahbm Archivo Histórico del Banco de México, ciudad de México, México.

\footnotetext{
${ }^{100}$ El de 19 de enero de 1931 se modificó la Ley reglamentaria sobre restituciones y dotaciones de tierra del 21 de marzo de 1929, persiguiendo restaurar la confianza.

${ }^{101}$ Almada, "Regidores", 2010.
} 
APPOR Archivo Particular Pascual Ortiz Rubio, ciudad de México, México.

CeHMC Centro de Estudios Históricos de México Carso, ciudad de México, México.

\section{Periódicos}

Boletín Financiero, ciudad de México, México.

El Economista, ciudad de México, México.

El Sol, Tegucigalpa, Honduras.

El Universal, ciudad de México, México.

Excélsior, ciudad de México, México.

Hoy, ciudad de México, México.

La Prensa, ciudad de México, México.

\section{Bibliografía}

Almada BAY, IgnACiO, "De regidores porfiristas a presidentes de la república en el periodo revolucionario explorando el ascenso y la caída del sonorismo", Historia Mexicana, El Colegio de México, vol. 60, núm. 2 (238), octubre-diciembre de 2010. Anaya Merchant, Luis, "De convenios y deudas en la revolución mexicana”, Boletín Fideicomiso Archivos Plutarco Elías Calles y Fernando Torreblanca, núm. 36, enero-abril de 2001.

"Del Banco Alemán Trasatlántico al Banco Mexicano de Comercio e Industria” en SAndra Kuntz y Horst Pietschmann, México y la economía atlántica, siglos XVIII-XX, México, El Colegio de México, 2007.

El Banco de México y la economía cardenista. Economía, cambio institucional y reglas monetarias, México, Universidad Autónoma del Estado de Morelos/Miguel Ángel Porrúa, 2011.

"El Mante o el ingenio del estatalismo revolucionario" en LUIS ANAYA, Mercedes Certucha y Laura Hernández, Historia económica regional, Tamaulipas, Universidad Autónoma de Tamaulipas, 2012 (Colección Lecturas Históricas de Tamaulipas, núm. III).

Comisión Nacional Bancaria, Sexto informe semestral a la Secretaría de Hacienda y Crédito Público, México, Talleres Gráficos de la Nación, 1928.

Elías Calles, Plutarco, La rehabilitación de la plata como moneda, México, Imprenta de la Secretaría de Relaciones Exteriores, 1933.

Gómez, Marte R., Vida política contemporánea: cartas de Marte R. Gómez, México, Fondo de Cultura Económica, 1978.

Gurría URgell, Oswaldo, Consideraciones acerca de los males que ha tenido el abandono de la plata en sus usos monetarios, VII Conferencia Internacional Americana, Mé- 
xico, Imprenta de la Secretaría de Relaciones Internacionales, 1934 (Del México Actual, núm. 14).

“Ingresos del Gobierno Federal, 1925-1979" en Instituto NACiOnal DE Estadística y Geografía (INEGi), Estadísticas históricas de México, México, Instituto Nacional de Estadística y Geografía, 2009.

Keynes, John M., The Economic Consequences of the Peace, Londres, Macmillan \& Co., 1920, [ca. 1919]. mica, 1996.

, Breve tratado sobre la reforma monetaria, México, Fondo de Cultura Econó, A Revision of the Treaty: Being a Sequel to the Economic Consequences of the Peace, Londres, MacMillan and Co. Limited, 1922. , A Tract on Monetary Reform, Londres, Macmillan, 1923.

"La previsión social en los Ferrocarriles Nacionales y líneas administradas", Oficina de Estudios Económicos de los Ferrocarriles Nacionales, asesoría del Comité Reorganizador, México, Palacio Nacional, 1932, mímeo.

Lippmann, Walter, Retorno a la libertad, México, uteha, 1940.

Mises, Ludwig von, Theorie des Geldes und der Umlaufsmittel, Múnich, Verlag von Dunkker \& Humblot, 1924.

, Liberalismus, Jena, Gustav Fischer, 1927. , Geldwertstabilisierung und Kojunturpolitik, Jena, Gustav Fischer, 1928. , Kritik des Interventionismus, Unterschngen zur Wirschaftpolitik und Wirtschafsideologie der Gegenwart, Jena, Gustav Fischer, 1929. , Die Ursachen der Wirtschaftsskrise, Tubinga, ICB Mohr, 1931. Grundproblem der Nationaökonomie, Jena, Gustav Fischer, 1933. , Las illusions du protectionnisme et de l'autarcie, París, Librarie de Medicis, 1938.

McElvaine, Robert S., The Great Depression. America, 1929-1941, Nueva York, Three Rivers Press, 1993.

Pani, Alberto J., Correspondencia particular de Marte R. Gómez y Alberto J. Pani, México, s. f. , Tres monografías, México, Cultura, 1941.

Apuntes autobiográficos, México, Librería de Manuel Porrúa, 1951, vol. II (Biblioteca Mexicana). Obsesiones y recuerdos, México, Talleres de A. Mijares Hno., 1953. , El problema supremo de México, México, s. e., 1955.

Riguzzi, Paolo, ¿Reciprocidad imposible? La política del comercio entre México y Estados Unidos, 1857-1938, México, El Colegio Mexiquense, 2003.

Secretaría de Hacienda y CRédito Público, La crisis económica en México y la nueva legislación sobre la moneda y el crédito, México, Cultura, 1933.

Silva Herzog, Jesús, México económico 1928-1930. Anuario estadístico de la oficina de estudios económicos de los Ferrocarriles Nacionales de México, México, Cultura, 1932. 
SuÁrez Dávila, Francisco, "Dos visiones de la política económica en México: un debate en la historia (1946 a 1970)" en Ma. Eugenia Romero Sotelo (coord.), Historia del pensamiento económico en México. Problemas y tendencias (1821-2000), México, Trillas, 2005.

, "Desarrollismo y ortodoxia monetaria (1927-1952): el debate entre dos visiones de política financiera mexicana" en LEONOR LudLOw y MA. EugENIA Romero Sotelo (coords.), Temas a debate. Moneda y banca en México 1884-1954, México, Universidad Nacional Autónoma de México, 2006.

Trigueros Saravia, Eduardo, La devolución de los depósitos bancarios constituidos en oro, México, Editorial México, 1934.

Turrent, Eduardo, "La reforma monetaria de 1931 y sus críticos. Debate interno y ecos del exterior" en Leonor Ludlow y María E. Romero Sotelo, Temas a debate. Moneda y banca en México, 1884-1954, México, Universidad Nacional Autónoma de México, 2006. 